\title{
Autistic Thinking, Literary Creativity as the Cause of Autism, and the Cure for Autism
}

\author{
by \\ Brian J. Beames, MBA, MT (ASCP) \\ Manager, Sole Member \\ Jared's Research, LLC \\ 2248 Meridian Blvd, Ste H \\ Minden, NV 89423-8620 \\ autismstudies4u@gmail.com
}

June 21, 2020

Keywords: Autism, Autistic Thinking, Bleuler, Literary Creativity, Egocentric, Perception

DOI: 10.17605/OSF.IO/WJURE

Preprint DOI: https://doi.org/10.31219/osf.io/7mnvh

For More Information: https://osf.io/wjure/ 


\begin{abstract}
The cause of autism, termed by Eugen Bleuler in 1911, has not been elucidated to this day. A scientific and logical approach can be utilized to eliminate potential causes and consider ideas not thought of before. Therefore, it is proposed that literary creativity is in fact the causative agent of autism and that a biological cause of autism will never be found. This notion is substantiated through its very unscientific early history and verified with observations made by both Leo Kanner and Hans Asperger. Without a mechanism of pathology, it is suggested that perception plays a major role in both the dissemination and the cure of autism. The Chi-square test of independence of statistics was used for hypothesis testing to show the low probability that pathology is likely to be found in the word "egocentricity," a term described to be one of the earliest precursors of autism. Therefore, due to the history of autism, autism is best defined as only a redefinition of the word "egocentricity."
\end{abstract}




\section{Introduction}

The world was first introduced to autism through the suggestion of its existence by Eugen Blueler written in 1911 (Moskowitz \& Heim, 2011) in the book Dementia Praecox Or The Group Of Schizophrenias. The book was originally written in German and was later translated to English in 1950 (Bleuler, Dementia praecox or the group of schizophrenias, 1911, 1950). In this book he originally described it, along with ambivalence, as a "basic (but not primary) symptom" (Maatz, Hoff, \& Angst, 2015, p. 45) of schizophrenia (Fusar-Poli \& Politi, 2008). More specifically he defined it as a "detachment from reality, together with the relative and absolute predominance of the inner life" (Bleuler, Dementia praecox or the group of schizophrenias, 1911, 1950, p. 63). However, in April 1913, Eugen Bleuler additionally introduced the concept of "autistic thinking," a concept understood and described by several others. Later in 1943, Leo Kanner wrote his famous paper entitled "Autistic Disturbances of Affective Contact” (Kanner, Autistic Disturbances of Affective Contact, 1943). In this paper, he suggested that the concept of autism could be applied to children. In addition to this, in 1944 an Austrian pediatrician by the name of Hans Asperger described a condition very similar to that of autism which was later termed as Asperger's Syndrome (Autism Independent UK, 2017). However, in 2016 it was recommended that this condition be integrated into the Autism Spectrum Disorders (BarahonaCorrea \& Filipe, 2016). This history has had a profound impact on the thinking of society and strongly influences people at this day and time. Despite this impact, the cause of autism currently remains elusive. This may be because the idea that the cause of autism is due to literary creativity has not been considered (Please see Appendix A for some modern-day examples of literary creativity). 


\section{A Scientific and Logical Approach}

To elucidate the cause of autism, all ideas need to be considered and systematically and logically eliminated. This includes both popular and unpopular ideas. It should also include ideas which have never been considered before. A popular idea exists currently which suggests that the cause of autism is some biological entity including genetics. However, other ideas which may not have been considered before include, but are not limited to, the notion that it is man-made through the utilization of literary creativity, or that the cause is due to evolution into what autism is today through the influence by the minds of men. It should be noted that the sin of anchoring as spoken of by Massimo Piattelli-Palmarini (Piattelli-Palmarini, 1994) should be considered and prevented when elucidating the cause of autism. This means that the popular ideas of the cause of autism should be questioned.

The evolution of autism, which is later described in this manuscript, describes how autism has changed through time but is only a force only after the advent of its creation of the term. This means that though the evolution of autism has had a powerful impact upon what autism is today, it does not provide a powerful explanation as to how autism came into being.

There might be other causes of autism which may exist, but which have not been described. However, they will not be considered simply because they have not been suggested by this author or any other author for that matter. This simply leaves two alternatives suggested above which include that it is of biological origin or that it came about due to literary creativity.

The notion that autism is of biological origin and the notion that it came about through literary creativity are opposite and contrarian to each other. One is both natural and logistic whereas the other notion, that it is of literary creativity, is artistic. If it is found that autism does indeed have a true mechanism of pathology through some biological entity, then this efficiently 
and soundly eliminates the notion that it came about through literary creativity. However, if it did indeed come about through literary creativity, then it can conclusively be deduced absolutely that a biological entity will never be found. Theories will abound to describe its cause (Feinstein, 2010), but they will always be proven wrong if they do not account for the creative element in its cause. Unfortunately, literary creativity does hold the disadvantage that it will have to be concluded through and by induction by the scientific community that it is indeed literary creativity which is the cause of autism. For example, it would be poor judgment to submit through the scientific method that the artwork by Johannes Vermeer entitled "Girl with a Pearl Earring" is indeed a piece of artwork. Induction satisfies that notion satisfactorily. Additionally, it is important to consider that the creation of new terms, such as autism, is a creative process in and of itself especially when the mechanism of pathology is not defined by the original authors.

It should also be noted that when the cause of autism is not known it is important to consider all the history regarding it. For example, modern day literature does acknowledge the quote describing autism as a "detachment from reality, together with the relative and absolute predominance of the inner life" (Bleuler, Dementia praecox or the group of schizophrenias, 1911, 1950, p. 63). However, modern day literature does not seem to acknowledge other quotes found from the same book which are quoted later in this manuscript. Modern day literature also does not seem to acknowledge Eugen Bleuler's writings which are found in the Journal of Insanity (Bleuler, Autistic Thinking, 1912) which is also acknowledged and discussed later on in this manuscript. This reference should be at the same level of importance as Leo Kanner's famous paper written in 1943 (Kanner, Autistic Disturbances of Affective Contact, 1943). These 
sources are important because the scientific community will never get an accurate idea of the cause of autism without considering these sources.

\section{Autistic Thinking}

Though it is true that Eugen Bleuler coined the term autism in his book "Dementia Praecox Or The Group Of Schizophrenias," it is entirely possible that he meant it as a way of thinking that he terms "autistic thinking" (Bleuler, Autistic Thinking, 1912). For example, in his book he mentions that "autism must not be confused with 'the unconscious.' Both autistic and realistic thinking can be conscious as well as unconscious" (Bleuler, Dementia praecox or the group of schizophrenias, 1911, 1950, p. 68). He also mentions that "we find normal autistic thinking in the form of exercising the capacity of combining ideas" (Bleuler, Dementia praecox or the group of schizophrenias, 1911, 1950, p. 374). Though it is rather unclear and confusing in his book that he meant it as a way of thinking, this becomes more clear in his address "at the opening exercises of the Henry Phipps Psychiatric Clinic [at] The John Hopkins Hospital [in] Baltimore, Maryland" (Bleuler, Autistic Thinking, 1912, p. 873). This address was given on the dates of April 16-18, 1913 and was later published in the Journal of Insanity with the date of, according to the document, July 1912 (Bleuler, Autistic Thinking, 1912). This address should be read in conjunction with this document.

A couple notable points provided by the address include the fact that autistic thinking is found in normal healthy individuals and is kept within limits by logical thinking. "Our political parties think autistically just as much and as little as the Romans and Greeks did...Often, especially in politics, autistic thinking serves instincts" (Bleuler, Autistic Thinking, 1912, p. 885). This quote from the address is powerful in the sense that it is clear Eugen Bleuler meant that there is a form of thinking (in the form of an adjective) that is separate and distinct from our 
modern day concept of autism (in the form of a noun) because it is illogical to conclude that a political party, a non-person entity, should be diagnosed with autism. He also mentions that "the health of the individual and of nations demands a balanced proportion of autistic and realistic function. The realistic must control the autistic. But the autistic contains most of our ideals" (Bleuler, Autistic Thinking, 1912, p. 886). This quote is important because it demonstrates that Eugen Bleuler meant that there are good attributes to autistic thinking which is an action that anyone can do.

One important consideration regarding autistic thinking is that Eugen Bleuler emphasized that it is only a temporary state of mind. He mentioned in his book the following:

"We have to distinguish between realistic and autistic thinking which exist side by side in the same patient. In realistic thinking the patient orients himself quite well in time and space. He adjusts his actions to reality insofar as they appear normal. The autistic thinking is the source of the delusions, of the crude offenses against logic and propriety, and all the other pathological symptoms. The two forms of thought are often fairly well separated so that the patient is able at times to think completely autistically and at other times completely normally. In other cases the two forms mix, going on to complete fusion."

(Bleuler, Dementia praecox or the group of schizophrenias, 1911, 1950, pp. 67-68)

This quote is important because it contradicts a belief about autism in our day which dictates that once a person is diagnosed with autism, they have it for life (Bates, 2013).

Eugen Bleuler discusses autistic thinking in his book called Lehrbuch der Psychiatrie. In it he mentions that "if we let our imagination run smoothly, in mythology, in dreams, in pathological conditions, in short in autistic thinking, we see a great detachment from experience that easily leads to nonsense, but which has its meaning as a symbol" (Bleuler, Lehrbuch der psychiatrie, 1916, p. 16) (Google, Inc., 2020). He also mentions that "this is how the most nonsensical delusional ideas are formed, and the way is cleared for exaggerated autistic thinking with its turning away from reality, its tendency to symbolism, to shifts and densifications" 
(Bleuler, Lehrbuch der psychiatrie, 1916, p. 281) (Google, Inc., 2020). These quotes are important because it shows that Eugen Bleuler thought that autistic thinking was a shift away from reality. In another section of his book, Eugen Blueler mentioned the following quote:

"While thinking, as it is usually described, is logical, realistic thinking, the most accurate or analogous repetition of ideas that the outside world offers, there is another thinking that is primarily directed by the affects and themselves do not care about reality, autistic thinking: the child and sometimes the adult dream during the day as a hero or inventor or something big; in the dream you can fulfill the most impossible desires in the most adventurous way; the schizophrenic day laborer marries a princess in his hallucinatory experiences. Of course, here, too, reality had to give its material to fulfill the wish: you cannot want to marry a princess unless you have somehow won the idea of a princess and marriage; but autism, moreover, is completely free and independent of all possibilities and all logical laws about what is offered, thereby not only ignoring reality, but actively splitting off what does not suit it: the day laborer is no longer the day laborer, but the ruler of the world."

(Bleuler, Lehrbuch der psychiatrie, 1916, p. 33) (Google, Inc., 2020)

This quote is important because it provides clarification and examples on Eugen Bleuler's ideas on what constitutes a loss of reality, a concept which is discussed later in this manuscript. It also shows that both children and adults do autistic thinking.

Another individual who spoke of autistic thinking, and who probably provided the clearest description of the term, is an individual by the name of Robert S. Woodworth, Ph.D. In his book "Psychology: A Study of Mental Life," he mentions that "dreaming, whether awake or asleep, is free imagination. It does not have to check up with any standard" (Woodworth, 1924, p. 508). He then says:

"Daydreaming, by itself, is an example of what is called "autistic thinking ", which means thinking that is sufficient unto itself, and not subjected to any criticism. Autistic thinking gratifies some desire and that is enough for it. It does not submit to criticism from other persons nor from other tendencies of the individual, nor does it seek to square itself with the real world."

(Woodworth, 1924, p. 508) 
Woodworth further discusses the fact that autistic thinking is indulged in by every imaginative person in moments of relaxation but at times can be taken to extreme by certain individuals. These individuals may interpret the world around them into something that it is not and it was implied by Woodworth that these individuals actually believe their imaginations to be truth even after you try to convince them otherwise (Woodworth, 1924).

Woodworth goes further and compares autistic thinking with different forms of thinking. Quoting form Woodworth:

"Autistic thinking is contrasted with realistic thinking, which seeks to check up with real facts; it may be contrasted also with socialized thinking, which submits to the criticism of other people; and it may even be contrasted with self-criticized thinking, in which the individual scrutinizes what he has imagined, to see whether it is on the whole satisfactory to himself, or whether it simply gratified a single or momentary impulse that should be balanced off by other tendencies."

(Woodworth, 1924, p. 509)

An observation that is important to consider from the writings of Woodworth is that there isn't any pathology to autistic thinking as he defined it. An individual can, whether extreme or not, snap back into reality and respond to individuals if they so desire. They can also choose to participate in realistic, socialistic, or self-criticized thinking at their will.

Another individual who spoke of autistic thinking was Jean Piaget. He is well known for his work on child development and for his theory on intelligence (Lefton, 1994). He also wrote a book entitled "The Language and Thought of the Child." In the book he mentions that "autistic thought...works chiefly by images" (Piaget, 1959, p. 26) and is symbolic in nature.

These writings concerning autistic thinking, which were written and understood by several individuals, are significant because had this understanding of autistic thinking remained the same throughout time the epidemic of autism, as it is understood today, simply would not have happened. This understanding of autistic thinking has the potential of benefitting those 
diagnosed with autism with providing them the knowledge that they are just like everyone else.

It is hoped that the scientific community and society at large embraces this very important concept of autistic thinking. All men and women should do this for the sole purpose of connecting with themselves.

\section{There Was No Pathology to Begin With}

Perhaps the strongest argument that autism will not be found with any pathology is that it originally did not start out with any pathology. If it did not start out with any pathology, then it is very logical to conclude that there is not any pathology today. The best clue that shows autism did not start out with pathology is a quote provided by Eugen Bleuler in his book describing what autism was before he termed it in 1911. He mentions that "of old, autism attracted attention, particularly among the French. The latter have described and stressed one aspect of it under such terms as autophilia, egocentricity, ego-hypertrophy, or augmentation du sens de la personalité; whereas the negative side was designated as perte du sens de la réalité, or perte de la function du réel." (Bleuler, Dementia praecox or the group of schizophrenias, 1911, 1950, p. 373). Utilizing the translation services from French to English provided by Google, Inc. and Loic Anthian, the phrase "augmentation du sens de la personalité" means "increased sense of personality" (Google, Inc., 2017). The phrase "perte du sens de la réalitê" means "loss of sense of reality" (Google, Inc., 2017). The phrase "perte de la function du réel" means "loss of the function of the real" (Google, Inc., 2017) (Anthian, 2017) or "loss of the meaning of reality" (Anthian, 2017).

One of the more interesting facts about this quote provided by Bleuler is the definition of the word "egocentric." According to the Oxford Dictionary, the word "egocentric" is "thinking only of oneself, without regard for the feelings or desires of others (Oxford Dictionaries, 2017). 
It is very clear from this definition that "egocentricity," the word provided from the quote, is more of a state of action caused by the purposeful decisions or cognitive activity of an individual rather than a state of physiological pathology. This is significant because the mechanism of pathology remains the same throughout time and, according to this principle, autism today should be a consequence of cognitive thought. Additionally, these concepts soundly eliminate any genetic component to autism which explains why the search for this genetic component has been relatively fruitless (See Appendix B for a more thorough discussion on this topic) (Zeliadt, 2017) (Fronteirs, 2017) (Matuszek \& Talebizadeh, 2009). In fact it was mentioned by Stuart Murray that "there are no biological markers for autism, neurological or otherwise" (Murray, Autism, 2011, p. 10). These arguments are just as easily applied to any of the other words or phrases provided in this quote by Eugen Bleuler. It should be noted that we are only limited to the definition of egocentricity according to the understanding that Eugen Bleuler had at the time. Additionally, it can also safely be argued from this quote provided by Eugen Bleuler that autism today is nothing more than the redefinition of the word "egocentricity." This is important because it should have a strong impact on the application of the concept of autism towards others. This quote by Eugen Bleuler, is perhaps the most important quote in the history of autism.

It is important to discuss the transition of egocentricity into autism. The process by which it transformed from egocentricity to autism came either due to a scientific process or it came about through some literary creativity process. If it came about through some scientific process which produced data, then that process would have been described by Eugen Bleuler, it would have been well known, and it would have been well studied to this day. It is very likely that this scientific process, which "uses reason and data as sources of truth" (Mason, Griffen, 
Merrill, \& Thorne, 1997), would have come about through observations with measurable effects experienced and seen due to pathological conditions such as a fever, food poisoning, or a virus. Additionally, this scientific process through pathology would have existed to this day and even before Eugen Bleuler observed it due to the concept of time symmetry (Mason, Griffen, Merrill, $\&$ Thorne, 1997) discussed later in this manuscript. However, it is highly likely that there isn't any data on egocentricity transitioning into autism given the fact that autism was intended to be more interpreted as a way of thinking rather than as condition. The fact that no scientific process was described by Eugen Bleuler through the production of scientific data gives strong credibility to the fact that it came about due to a very unscientific literary creativity process. This explains why a scientific cause is not known to this day and why a scientific biological cause will not be found in the future. The lack of scientific findings is scientifically consistent with the explanation that it came due to a literary creativity process. It is also important to note that the popular held notion that it is of biological origin is not consistent with current day scientific findings (or the lack thereof). In fact, it was even intimated by Leo Kanner that autism is not due to a biological cause when he mentioned that:

"It is true that I have not considered a brain tissue biopsy in any of the autistic patients. Neither the clinical neurological findings nor the electroencephalograms nor the subsequent developments seemed to me to justify such a procedure. Even those patients who have withdrawn to the point of functional idiocy or imbecility show, especially in their behavior with puzzles and form boards, residual oases of planned mental activity which should deter one from thinking in terms of a degenerative organic process." (Kanner, Problems of Nosology and Psychodynamics of Early Infantile Autism, 1949, p. 417)

This is important to acknowledge because it recognizes that even Leo Kanner encouraged others to rule out that autism is due to a biological origin. It also forces the concept of autism into 
being just a concept or an idea without any biological entity. This also means that it is rather useless for individuals in our day to seek out a biological cause.

A quote which verifies that autism is caused by literary creativity was provided by Hans Asperger in his 1944 paper which says that "the name 'autism', coined by Bleuler, is undoubtedly one of the great linguistic and conceptual creations in medical nomenclature" (Asperger, 1991). The wording of this quote should be strongly considered. Hans Asperger did not say that autism was a great discovery such as the discovery of malaria on a microscope slide (Cox, 2010). He did not say it was an observation such as seen when individuals contract an infection only to later exhibit a measurable fever. Rather, he said it was a creation thus indicating and validating it was brought about due to literary creativity.

\section{Statistical Analysis}

Studies can be done by others to determine if pathology exists due to egocentricity thus proving scientifically the existence of autism. However, it is important to note that the results of these studies have the potential to show that there is not any pathology associated with the word egocentricity. In fact, it should logically be predicted that this be the case. Had Eugen Bleuler performed these studies himself, it is entirely possible that he may have admitted that there was not any etiology to autism and that autism was due to literary creativity. Had he lived in our day these studies would have been required of him.

The exact studies which can be done is to find individuals with high, moderate, low, and no egocentricity (Brown, 2010) and determine if there is any pathology associated with each of these categories. These values can be arbitrarily assigned and defined by individuals in our day due to the lack of information and vagueness provided by Eugen Bleuler. All individuals in the population can be used to look for pathology according to Phase I clinical trials dictated by the 
International Conference of Harmonization. In this case, the independent variable is the level of egocentricity whereas the dependent variable is whether pathology is present due to that egocentricity. It should be noted that egocentricity, like social impairment, cannot be quantified. It is predicted that the result will remain relatively constant regardless of the sample size, the number of samples, and the sample category. This means that one sampling with multiple data points is enough to use for statistical purposes. Since it is expected that there will be no pathology due to egocentricity, it is expected that the data will be non-parametric or distribution free. Due to this fact, and the fact that the dependent variable is measured at the nominal level, binary, and qualitative in nature, the Chi-square test of independence (McHugh, 2013) was chosen as the statistical tool amongst the many tools available (Marusteri \& Bacarea, 2010) in order to conduct hypothesis testing. For this study, the alternative hypothesis $\left(\mathrm{H}_{1}\right)$ states that biological pathology does not exist due to egocentricity whereas the null hypothesis $\left(\mathrm{H}_{0}\right)$ states that biological pathology exists due to egocentricity.

A random number generator (Stat Trek, 2018) was utilized (Number of random numbers: 4, Minimum value: 0, Maximum value: 99,999, Allow duplicates: True) to create a sampling of individuals where pathology was not exhibited due to egocentricity. This same random number generator (Stat Trek, 2018) was utilized (Number of random numbers: 4, Minimum value: 5, Maximum value: 40, Allow duplicates: True) to create a sampling of individuals which exhibited pathology due to egocentricity. It is important to note that these sampling numbers are a prediction of what might be expected to be seen if sampling were to actually be done. Even though it is anticipated that no pathology is to be seen in all of the samples collected, the few positive samples seen in the pathology exhibited column account for the few false positives which might be seen. False negatives are not considered because it is expected that no pathology 
will be exhibited in any of the samples. Besides, if there was pathology present due to egocentricity, the numbers found in the pathology exhibited column would be significantly higher.

Table 1. Results of Pathology Due to Egocentricity.

\begin{tabular}{|c|c|c|}
\hline Level of Egocentricity & Pathology Not Exhibited & Pathology Exhibited \\
\hline High & 20751 & 18 \\
\hline Moderate & 10492 & 11 \\
\hline Low & 88283 & 26 \\
\hline None & 57613 & 19 \\
\hline
\end{tabular}

The next step is the calculation of the marginals. This is the first step in the directions provided by McHugh (McHugh, 2013) on how to do a Chi-square test of independence.

Table 2. Calculation of Marginals.

\begin{tabular}{|c|c|c|c|}
\hline $\begin{array}{c}\text { Level of } \\
\text { Egocentricity }\end{array}$ & $\begin{array}{c}\text { Pathology Not } \\
\text { Exhibited }\end{array}$ & Pathology Exhibited & $\begin{array}{c}\text { Row Marginals } \\
\text { (Row Sum) }\end{array}$ \\
\hline High & 20751 & 18 & $\mathbf{2 0 7 6 9}$ \\
\hline Moderate & 10492 & 11 & $\mathbf{1 0 5 0 3}$ \\
\hline Low & 88283 & 26 & $\mathbf{8 8 3 0 9}$ \\
\hline None & 57613 & 19 & $\mathbf{5 7 6 3 2}$ \\
\hline $\begin{array}{c}\text { Column Marginals } \\
\text { (Sum of the Column) }\end{array}$ & $\mathbf{1 7 7 1 3 9}$ & $\mathbf{7 4}$ & \\
\hline
\end{tabular}


The next step is to calculate the cell expected values and the individual cell Chi-square values $\left(\chi^{2}\right)$ according to McHugh (McHugh, 2013).

Table 3. Cell Expected Values and (Cell Chi-square Values).

\begin{tabular}{|c|c|c|}
\hline Level of Egocentricity & Pathology Not Exhibited & Pathology Exhibited \\
\hline High & $20760.33\left(4.19 \times 10^{-3}\right)$ & $8.67(10.03)$ \\
\hline Moderate & $10498.61\left(4.17 \times 10^{-3}\right)$ & $4.39(9.97)$ \\
\hline Low & $88272.12\left(1.34 \times 10^{-3}\right)$ & $36.88(3.21)$ \\
\hline None & $57607.93\left(4.45 \times 10^{-4}\right)$ & $24.07(1.07)$ \\
\hline
\end{tabular}

The individual cell $\chi^{2}$ values are then "summed to obtain the $\chi^{2}$ statistic for the table. In this case, the $\chi^{2}$ is" (McHugh, 2013, p. 146) 24.290. The degrees of freedom for this data set is 3 (McHugh, 2013). Utilizing the Ch-distribution function found in Microsoft Excel software the $\mathrm{P}$ value was calculated to be $2.17 \times 10^{-5}$. Since the $\mathrm{P}$-value in this case is less than $\mathrm{P}<0.05$, the null hypothesis is rejected while the alternate hypothesis is accepted. Rejecting the null hypothesis in this case is safe since the behavior of the data contradicts the assumption of the null hypothesis. This means that if testing was to be done and the results were to be similar to these predicted values, then it could be said that biological pathology does not exist due to egocentricity.

Cramer's V test (McHugh, 2013) was used to find the statistical strength of these statistical values. Therefore, utilizing the square root function found in Microsoft Excel software and the equation of the $\mathrm{V}$ test (McHugh, 2013), the V value was calculated to be 0.012 . 
A Fisher's exact test was not used in this analysis due to the fact there were more than two rows (McHugh, 2013). An analysis was done by the author utilizing the maximum likelihood ratio Chi-square test (McHugh, 2013) (G test) with the $\mathrm{G}$ formula (Ozdemir \& Eyduran, 2005) where the true expected number values of 0 was found for those with pathology being exhibited for each level of egocentricity. This was done to show that the best statistical test to use was the Chi-square test with the hypothetical false positives being greater than 5 .

Table 4. Results of Pathology Due to Egocentricity with True Expected Values.

\begin{tabular}{|c|c|c|}
\hline Level of Egocentricity & Pathology Not Exhibited & Pathology Exhibited \\
\hline High & 20751 & 0 \\
\hline Moderate & 10492 & 0 \\
\hline Low & 88283 & 0 \\
\hline None & 57613 & 0 \\
\hline
\end{tabular}

The calculation of marginals was calculated from the previous chart. 
Table 5. Calculation of Marginals.

\begin{tabular}{|c|c|c|c|}
\hline $\begin{array}{c}\text { Level of } \\
\text { Egocentricity }\end{array}$ & Pathology Not & Pathology Exhibited & Row Marginals \\
Exhibited & 20751 & 0 & $\mathbf{2 0 7 5 1}$ \\
\hline High & 10492 & 0 & $\mathbf{1 0 4 9 2}$ \\
\hline Moderate & 88283 & 0 & $\mathbf{8 8 2 8 3}$ \\
\hline Low & 57613 & 0 & $\mathbf{5 7 6 1 3}$ \\
\hline None & $\mathbf{1 7 7 1 3 9}$ & $\mathbf{0}$ & $\mathbf{1 7 7 1 3 9}$ \\
\hline (Sum of the Column) & & & \\
\hline
\end{tabular}

Cell expected values and cell $\mathrm{G}$ values were then calculated.

Table 6. Cell Expected Values and (Cell G Values).

\begin{tabular}{|c|c|c|}
\hline Level of Egocentricity & Pathology Not Exhibited & Pathology Exhibited \\
\hline High & $20751(0)$ & $0(\mathrm{CNP})$ \\
\hline Moderate & $10492(0)$ & $0(\mathrm{CNP})$ \\
\hline Low & $88283(0)$ & $0(\mathrm{CNP})$ \\
\hline None & $57613(0)$ & $0(\mathrm{CNP})$ \\
\hline
\end{tabular}

Where CNP = Calculation not possible

It is recommended that other researchers conduct these tests of pathology as it is currently beyond the resources of the author. If done, it would be the first time in the history of autism to perform scientific studies on autism as Eugen Bleuler first conceptualized it. These tests would verify or challenge the idea that autism is a valid scientific concept. However, it is important to 
observe that induction should be and is enough to conclude that there is not any pathology stemming from egocentricity rendering this study useless or not needing to be done. This is consistent with the observation of pathology not being exhibited by humanity even though the number of times egocentricity has been expressed by everyone has been large.

\section{The Observer Bias}

The observer bias has happened in the history of autism. The observer bias "occurs when researchers alter the outcome of a study" (GoodTherapy.org, 2017) and it usually occurs very subtly. It can simply occur by an observer looking for something that he has in mind when another observer who sees the exact same thing but is not looking for anything in particular will come up with an entirely different conclusion in terms of what they see. A good example of this was mentioned by Uta Frith. She mentioned the following:

"In 1943 [Leo] Kanner introduced the label early infantile autism for a type of disorder hitherto unrecognized as a clinical entity, although it is possible to find earlier case descriptions. These early descriptions had failed to leave their mark because nobody pointed out their significance or gave them a name. After Kanner, every major clinic immediately found cases which fitted the category of early infantile autism" (Frith, 1991, p. 5).

If these same clinics were never even looking for the condition, then the possibility exists they would have perceived these exact same cases to be entirely normal.

Others have observed similar findings. For example, Stuart Murray mentioned that "the clinical observation of autism was brought into being by the process of looking for it, one of voyeuristic authority, and then generalizing from the results subsequently found" (Murray, Autism, 2011, p. 51). However, and like previously mentioned, the opposite is true that a different set of conclusions could be made if individuals were not looking for autism. 
The observer bias is evident not just in the theories and ideas put forth by Eugen Bleuler, Leo Kanner, or others, as they were observing patients, but also in studies performed by Anthony and Cameron. The nurses in these studies would record observations of behavior of children in language like that of a social worker. This language was then later corrected by Anthony and Cameron. "After further instruction and requests by the doctors to focus on the boy's ['autistic behavior', the nurses] began to produce detailed accounts of the child's individual [behavior] and speech" (Evans, 2017, p. 151). Thus, by looking for these "autistic traits," they were looking for evidence to confirm their suspicions which had the unintended consequences of skewing and altering the observations of children.

If autism were to truly exist, independent of this observer bias, then autism would have been experienced by mankind very much like the diseases of old where diseases and sicknesses would develop inside themselves through no action of their own while not exactly knowing the cause. For example, individuals would have for some mysterious reason developed swelling in the groin due to their unknown infection of Yersinia pestis, the organism causing the Bubonic Plague. Another example includes individuals experiencing swelling of their abdomen (due to hepatosplenomegaly) accompanied by fatigue. These individuals thought this mysterious sickness was caused by bad air (hence the name Malaria) and they sought to evade this bad air by going to places thought to have good air, such as Buenes Aires, Argentina.

From these examples, the first step in discovering the etiology of disease is usually the experiencing of symptoms through some form of a disease. This is usually then followed by the discovery of the cause of the disease at times utilizing Koch's Postulate (MedicineNet.com, 2016). Most generally, a cure for that disease at times then follows. 
Yet, in contrast with autism, there was no such history as this. To begin with, there weren't any symptoms experienced by mankind prior to 1900. It was then suggested that it existed. Individuals then sought to apply autism to their lives, or more importantly, to the lives of others through diagnosis, all the while struggling to find the cause with no cause to be found.

Therefore, in this case it would be prudent to explore the idea of a thought experiment. This experiment consists of asking the question that if autism were to never be suggested in the first place, would mankind spontaneously and indiscriminately experience the symptoms of autism. In other words, would those who consider themselves to be normal spontaneously come down with the symptoms of autism as it is understood today (completely devoid of the observer bias)? It has been the experience of a vast number of individuals that this simply does not happen, and this observation is consistent with what was found among men before 1900. This is important because it suggests the possibility that autism would not have been a problem today had its suggestion of its existence not occurred through literary creativity and it also suggests that the observer bias occurred through the creation of autism itself. These observations, and the concept of autism itself, must be consistent with the notion of time symmetry which dictates that the laws of nature remain the same through time and that "they are the same now as they were in the distant past and will be in the future" (Mason , Griffen, Merrill, \& Thorne, 1997, p. 3). It is also important to state that though biases may exist amongst any authors who have written about autism, the one entity which does not care about any biases or philosophical ideals is the mechanism of pathology itself. This should be important to consider in the quest to elucidate the cause of autism. 


\section{Evolution of Autism}

In addition to the observer bias that exists in the history of autism, autism itself has undergone some significant evolution. As discussed earlier it originated as egocentricity and then was reformulated by Eugen Bleuler into a symptom of schizophrenia in the form of autistic thinking. Autism underwent further modifications best described in Bonnie Evans' book “The Metamorphism of Autism." The analysis provided by this author is spectacular and should be read in conjunction with this document. In the book the author effectively argued that autism transformed into the exact opposite of what it originally meant from one in which individuals had "hallucinatory dreamlike imaginary thought" (Evans, 2017, pp. 189-190) into the definition of the lack of this type of thinking. Additionally, Ian Hacking mentioned that "the conception of autism has evolved" (Hacking, 2006) and that dictionaries have changed its meaning over time (Hacking, 2006).

There are other ways that autism has evolved. For example, in 1956 Leo Kanner "decided to narrow the criteria for early infantile autism to two main ones" (Feinstein, 2010, p. 47): "a will to self-isolation, present from birth, that he called extreme autistic aloneness" (Silberman, 2015, p. 182) and "a fear of change and surprise, which Kanner memorably christened an anxiously obsessive desire for the maintenance of sameness" (Silberman, 2015, p. 182). "For decades, Kanner maintained that his syndrome was monolithic by definition, limited to childhood, and vanishingly rare" (Silberman, 2015, p. 41). However, today the criteria for autism is provided by two sources. The first is the fifth edition (published in 2013) of The American Psychiatric Association's Diagnostic and Statistical Manual of Mental Disorders (DSM-V) and consists of five criteria (see the Appendix C to see this criteria) (The American Psychiatric Association, 2013). The second source comes from the 11th edition of the 
International Classification of Diseases and has an additional seven subtypes of autism (see Appendix D to see this criteria) (Research Autism, 2018). These differences between the diagnostic criteria of Leo Kanner to that of today shows that "widening of the diagnostic criteria" (Murray, Autism, 2011, p. 82) has occurred.

In fact, others have suggested that this broadening or widening of the criteria of autism was intentional. Steve Silberman elaborated upon this point. He said:

"By expanding Kanner's narrow definition of his syndrome to include more mildly impaired children and adults, [Lorna Wing] had expected estimates of autism prevalence to rise. That was precisely the point: making the diagnosis available to more people, so that they and their families wouldn't have to struggle along without help as they had in the 1960s."

(Silberman, 2015, p. 421)

This quote successfully demonstrates that the evolution of autism was intentional. Due to these actions it also means that it is conscious cognitive thoughts, synonymous and equal to bacteria and viruses, which drives the increased rates of the diagnosis of autism.

The evolution of autism even occurred in the mind of Hans Asperger over the space of a few short years. It was observed that:

"In 1937, Asperger had cautioned against creating diagnoses; in 1938, only months after the Nazi annexation of Austria, he had described autism as a 'well-characterized group of children.' In 1941, this became 'a group of abnormal children.' By 1944, Asperger was employing fascist rhetoric of the Volk, pronouncing autistic children to be outside of 'the greater organism."”

(Sheffer, 2018, pp. 214-215)

In this specific case pertaining to Hans Asperger, it could be said that outside cultural influences and forces helped to contribute to the evolution in how he both described autism and applied it to children.

This evolution is significant because it makes it nearly impossible to elucidate the cause of a condition, such as autism, if the definition and meaning of it has changed so much over time. 
It is impossible to find the cause based upon the downstream changed meaning of the term especially if its history is not taken into consideration. Therefore, in order to elucidate the cause, one needs to go back to the upstream, or the original meaning of the term, and to learn how it was originally created. Without this evolution, it is entirely possible that autism would have remained to be autoerotism, egocentricity, or autophilia, and simply would not have existed in this day. Additionally, if there was a mechanism of pathology for autism then this evolution that existed in its history simply would not have happened. Without a mechanism of pathology, any description of autism can exist thus explaining its ability to change over time. However, the fact that it has indeed changed meanings through time strengthens the argument that autism came about through literary creativity.

\section{Assumptions of Leo Kanner}

It is an especially important critical observation of Leo Kanner, who suggested that an inability to form normal social interactions with others is an innate condition, was an assumption. He writes:

"We must, then, assume that these children have come into the world with innate inability to form the usual, biologically provided affective contact with people, just as other children come into the world with innate physical or intellectual handicaps. If this assumption is correct, a further study of our children may help to furnish concrete criteria regarding the still diffuse notions about the constitutional components of emotional reactivity. For here we seem to have pure-culture examples of inborn autistic disturbances of affective contact." (Kanner, Autistic Disturbances of Affective Contact, 1943, p. 250)

This can be interpreted in such a way that these assumptions are a hypothesis which should then be applied and tested through the scientific method. Thus, an assumption should not be confused with a verifiable, repeatable, and valid scientific conclusion or fact. Additionally, assuming Leo Kanner's assumption is true does not make it into or constitute a scientific fact. This simply 
means that Leo Kanner's assumption will always remain an assumption until scientifically proven otherwise. Additionally, Leo Kanner had a belief that he was describing a new condition (Feinstein, 2010). This belief needs to be backed up by truths which are external to Leo Kanner in order to verify this belief. These truths are usually found through data with a clinical manifestation.

It is important to consider that an assumption always contains an element of probability that the premise, or the conclusion of the assumption, may be incorrect. A great example of this in history occurred in 1845 when Sir John Franklin was seeking to discover a route through the Northwest Passage. He assumed that he was going to return home by boat as this was his mode of travel at the time. This assumption later proved to be fatal to both him and his $128 \mathrm{men}$ as his boat got caught up in the ice flows which run rampant in that area (Productions, 2005).

Thus, it is important to observe that Leo Kanner did not consider the possibility that his assumption could be incorrect. He also didn't provide any empirical studies which proved scientifically that autism is indeed an innate condition. He only confirmed it with his own confirmation bias (Kanner, Problems of Nosology and Psychodynamics of Early Infantile Autism, 1949). These studies are required of scientists in our day. It should also be noted that his argument, that it is an innate condition, runs contrary to the quote by Eugen Bleuler that "the patient is able at times to think completely autistically and at other times completely normally" (Bleuler, Dementia praecox or the group of schizophrenias, 1911, 1950, p. 67). This shows that Leo Kanner utilized just as much literary creativity to describe the behavior of his 11 patients. If he would have read the words of Eugen Bleuler then he would have recognized that they eventually would have had the ability to go in and out of normal thinking, especially as they got older. The fact that these two major authors of autism contradict each other is important to 
consider. It is not ideal to discuss which quote is valid and which one is not. Rather, it is best to take both quotes into consideration and to use this information to question the legitimacy of autism. After all, the principle of noncontradiction applies to this situation which states that "of two contradictory propositions, both cannot be true" (Mason, Griffen, Merrill, \& Thorne, 1997, p. 3).

One very important quote provided by Leo Kanner in his 1949 paper with the title of "Problems of Nosology and Psychodynamics of Early Infantile Autism" published in the American Journal of Orthopsychiatry is that he said that "my search for autistic children of unsophisticated parents has remained unsuccessful to date" (Kanner, Problems of Nosology and Psychodynamics of Early Infantile Autism, 1949, p. 421). This should have been a major clue to him that autism had no mechanism of pathology because organisms grown on a Petri dish or viruses grown in viral culture medium do not discriminate based upon the sophistication of its host. Additionally, genetic diseases discriminate based upon genetics and not upon sophistication. However, to Leo Kanner's credit, he simply may not have been aware of this technology even though it existed at the time he wrote that specific paper. In fact, Adam Feinstein wrote concerning this quote that:

"Kanner's original sample was also biased, and it may have been this which led to his surprising conclusion about the children being of normal or above-normal intelligence. As the Swedish autism authority, Christopher Gillberg, noted to me: 'Kanner's original cases were overselected, with the children coming from the higher classes, because those were the parents who were aware of his writings. That's why Kanner got the impression that autism all came from the upper classes."” (Feinstein, 2010)

This quote demonstrates where Kanner concluded that autism is not found in children of unsophisticated parents and it demonstrates that Kanner thought that those diagnosed with autism were rather intelligent. 
Leo Kanner in this same paper encouraged others to not conclude that autism is due to a biological cause when he mentioned that there are "residual oases of planned mental activity which should deter one from thinking in terms of a degenerative organic process." (Kanner, Problems of nosology and psychodynamics of early infantile autism, 1949, p. 417). It is suggested that this quote contradicts his 1943 paper where he assumes that autism is innate. This is because it is implied that a degenerative organic process is occurring if in fact autism is innate.

\section{Literary Creativity of Leo Kanner, Hans Asperger, and Lorna Wing}

It is undeniably clear that both Leo Kanner and Hans Asperger were heavily influenced by the thoughts and writings of Eugen Bleuler. Adam Feinstein, in his book A History of Autism, mentioned the following:

"It may seem odd that both Asperger and Kanner chose to use Bleuler's term 'autism,' especially given that Kanner was convinced that what he described was a unique syndrome. But Marc Bush has pointed out to me that both men were likely to have studied the same textbook, namely the fifth edition of Bleuler's 1930 Lehrbuch der Psychiatrie...Christopher Gillberg told me he believed they chose the term 'autism' because the psychiatrists of the 1930s and 1940s were influenced by the terminology of both Bleuer and Kraepelin.” (Feinstein, 2010, p. 26)

This is important to know because if true then this means that the ideology of both Hans Asperger and Leo Kanner were deeply rooted from the ideology set forth by Eugen Bleuler. The likelihood of this quote by Feinstein not being true is low since the term "autism" was indeed created by Eugen Bleuler. This means that the ideas set forth by both Hans Asperger and Leo Kanner should have fit underneath the umbrella set forth by Eugen Bleuler. The problem is that both deviated from the ideas set forth by Eugen Bleuler through their own literary creativity.

For example, this was evidenced by the fact that in 1944 Leo Kanner introduced the term "Early Infantile Autism" (Kanner, M.D., Early Infantile Autism, 1944). He later described the 
coinage of that term at a lecture in a meeting with the American Psychiatric Association in New York on May 4, 1965. This lecture was published in the journal Behavioral Science the same year with the title of "Infantile autism and the schizophrenias" (Kanner, M.D., Infantile Autism and the Schizophrenias, 1965). In that lecture he said that "in my search for an appropriate designation, I decided in 1944, after much groping, on the term early infantile autism, thus accentuating the time of the first manifestations and the children's limited accessibility" (Kanner, M.D., Infantile Autism and the Schizophrenias, 1965, p. 412). This introduction of this term deviated from the writings of Eugen Bleuler because it was never mentioned by Eugen Bleuler that autism or autistic thinking was found in infants (Bleuler, Autistic Thinking, 1912) (Bleuler, Dementia praecox or the group of schizophrenias, 1911, 1950) (Bleuler, Lehrbuch der psychiatrie, 1916). It should be noted that the article written by Leo Kanner in 1965 gave definitive proof that Leo Kanner studied Bleuler's writings through quoting him. Despite this fact, it is odd that Leo Kanner never even mentioned the concept of autistic thinking in four of his publications (Kanner, Autistic Disturbances of Affective Contact, 1943) (Kanner, M.D., Early Infantile Autism, 1944) (Kanner, M.D., Infantile Autism and the Schizophrenias, 1965) (Kanner, Problems of Nosology and Psychodynamics of Early Infantile Autism, 1949) even though this was specifically mentioned in one of Eugen Bleuler's textbooks of psychiatry (edition not known) (Bleuler, Lehrbuch der psychiatrie, 1916) and discussed by Hans Asperger (Asperger, 1991). Some have even suggested that Leo Kanner plagiarized Hans Asperger's work (Feinstein, 2010) even though this can't be proven definitively. However, this is a strong possibility since Hans Asperger's former diagnostician, Georg Frankl, later worked underneath Leo Kanner (Silberman, 2015). Due to these discrepancies, it is possible that Leo Kanner simply misunderstood the words of Eugen Bleuler. However, this is impossible to verify at this time as 
this can only be verified through direct communication with Leo Kanner which can't be done due to his death.

Hans Asperger described autism as an "autistic psychopathy" (Asperger, 1991) thus introducing a negative stigma and a deviation from Eugen Bleuler's original "autistic thinking" discussed earlier in this manuscript. This new term was "steeped in the principles of Nazi child psychiatry" (Sheffer, 2018, p. 61) and was a reflection of the theories of social disconnection already in existence in Germany during the 1930s (Sheffer, 2018). "Asperger did not introduce his definition of autistic psychopathy until Nazism controlled his world — and when he did, he defined it in terms of Reich rhetoric and values" (Sheffer, 2018, p. 85). Attention should be brought to the fact that the word "psychopathy" was not associated with autism or autistic thinking in at least three of Eugen Bleuler's sources (Bleuler, Autistic Thinking, 1912) (Bleuler, Dementia praecox or the group of schizophrenias, 1911, 1950) (Bleuler, Lehrbuch der psychiatrie, 1916) thereby demonstrating that Eugen Bleuler never intended autism or autistic thinking to be a psychopathy. Regardless, Lorna Wing, attempting to ameliorate any negative stigma Hans Asperger's term brought about and to be altruistic herself, created a new term of her own called "Asperger's Syndrome," thus birthing a new label. It could have been possible and would have been better had Lorna Wing argued against Hans Asperger's terminology by asserting that autistic psychopathy was a product of Nazi Germany culture used at times to deny children their humanity (Sheffer, 2018) and that the word "psychopathy" was never mentioned by Eugen Bleuler thus deviating from Eugen Bleuler's original intent. This would have had the effect of delegitimizing Hans Asperger's label without creating a new one. Doing this would have had a strong impact on the psychological outcome of others as no one would not have had to live with the label of Asperger's Syndrome. It should also be observed that Lorna Wing, 
before she died, expressed regret and remorse for having created the label "Asperger's Syndrome" and for making the public aware of Hans Aspergers' writings (Sheffer, 2018)

(Feinstein, 2010). In fact, she mentioned that "she is not convinced...that her coinage was altogether a positive development" (Feinstein, 2010, p. 204). She goes on to say that:

"I wish I hadn't done it. I would like to throw all labels away today, including Asperger's syndrome, and move towards the dimensional approach. Labels don't mean anything, because you can get such a wide variety of profiles"

(Feinstein, 2010, p. 204)

This remorse should be recognized by the scientific community and the world at large.

Therefore, it would be ideal to honor Lorna Wing's wishes and try to return to the same state as it was before she introduced that label. Fortunately, the trend is moving in that direction as the term "Asperger's Syndrome" will be excluded from ICD-11 by incorporating it in the Autism Spectrum Disorder (Reed, et al., 2019). The history of Asperger's Syndrome is a great example where it is not always ideal to create a label especially if it is not backed up by any description of pathology. The world at large could have always lived without the label as it was not affecting anyone before it was created.

It should be noted that Asperger's Syndrome was differentiated as a distinct entity from that of autism without the utilization of any observable and measurable clinical data thus leading to its creation through literary creativity (Wing, 1981). Like autism, it was founded completely based upon the behavior of an individual (Wing, 1981). This means that Asperger's Syndrome, in addition to autism, doesn't have any pathology associated with it and can be cured in the same manner as autism discussed below. This also can be done due to Asperger's Syndrome being incorporated into the classification of our modern-day understanding of autism (Barahona-Correa \& Filipe, 2016). 


\section{Assuming the Presence of Pathology}

For autism to truly exist as an etiological agent in the innate biological form, there should be a clinical presentation of it, verified with data. However, this is most likely not to be found given the history of autism described above. In fact, years of genetic studies seem to indicate the exact opposite of Leo Kanner's assumption in that autism is not an innate condition. Therefore, to assume that autism exists in biological form without a clinical presentation is to assume that there is pathology in processes in which there is none. This especially should be considered if autism is caused due to literary creativity.

As described before, autism was first a way of thinking which then transformed into the lack of imaginative thinking (Evans, 2017). During this transition period, a conclusion was drawn out that the innate form of autism could best be attributed to a brain abnormality. Quoting from Uta Frith:

"Autism is due to a specific brain abnormality. The origin of the abnormality can be any one of three general causes: genetic fault, brain insult or brain disease. Autism is a developmental disorder, and therefore its [behavioral] manifestations vary with age and ability. Its core features, present in different forms, at all stages of development and at all levels of ability, are impairments in socialization, communication and imagination." (Frith, 1991, p. 2)

Although this explanation provides a description of our modern-day interpretation of autism, it does not take into consideration the entirety of the history of autism. This includes the notion of autistic thinking described earlier which, according to others, normal people do. Thus, in general, it is advisable to not assume that there is pathology in processes in which there is none.

\section{Role of Perception in the History of Autism}

Perception has played a role in the history of autism. Bonnie Evans in her book, The Metamorphosis of Autism, mentioned the following: 
"There were several cases in which some professionals saw autism and autistic features whilst others saw none. For example, one child had been diagnosed with autism in 1976 at the age of four by an educational psychologist who said that all the 'criteria of childhood autism are present'. He was also seen by a consultant child psychiatrist, Dr Ross, who thought that the boy was 'probably suffering from childhood autism'. The parents then took the child to see Dr Hugh Jolly, consultant paediatrician at the Charing Cross Hospital, who did not think that the boy was autistic and 'the label of autism was thus removed by Dr Jolly'. Dr Mackay, consultant paediatrician at the Royal Manchester Children's Hospital, also thought that the boy 'did not show the classic features of autism'. When the boy was later referred to the Maudsley at the age of eight, Rutter argued that he was 'suffering from childhood autism in a mild form"" (Evans, 2017, p. 284)

This is a great example that shows the boy's diagnosis was completely reliant upon another person's perception of him. This instance is like the Rosenhan hoax (Grinker, 2007) in that it was perception which led to the diagnosis.

Another way that perception has played a role in the history of autism is through the actual experiences of Leo Kanner. Adam Feinstein mentioned the following:

"The consensus still held in the 1950s that autism was an extremely rare condition. In 1958, Kanner himself wrote that he had seen fewer than 150 cases of autism in 19 years - fewer than eight patients per year-despite the fact that his Baltimore clinic served as what he called "a sort of diagnostic clearing-house" and that the patients came from all over the United States and even from as far afield as South Africa. Bernard Rimland said that Kanner had informed him personally that only 1 child in 10 brought to him after being diagnosed as "autistic" by others was actually a true case of autism...Kanner did quickly become irritated at the way his term was, in his eyes, being abused."

(Feinstein, 2010, pp. 46-47)

The quote shows that perception played a major role in the diagnosis of autism even in the earliest days of the history of autism. In fact, Leo Kanner later on "complained that his concept of early infantile autism ('I could not think of a better name,' he added) had been applied so broadly that 'the term was used as a pseudodiagnostic wastebasket for a variety of unrelated conditions"” (Silberman, 2015, p. 270). Additionally, these quotes by Leo Kanner shows that 
other professionals over-diagnosed autism according to Leo Kanner's much more narrow interpretation thus raising the possibility that we do the same today.

Even Hans Asperger thought that perception played a role in the history of autism. "He admitted it was hard to generalize about autistic children since 'the findings can be contradictory and different testers can come to different intelligence estimates"” (Sheffer, 2018, p. 175).

Perception can account for the age discrepancy found in the history of autism. Leo Kanner provided the observation that autistic traits were found in children which were described in his famous paper detailing 11 case studies (Kanner, Autistic Disturbances of Affective Contact, 1943) and in his paper where he created the term "early infantile autism" (Kanner, M.D., Early Infantile Autism, 1944). However, Eugen Bleuler "referred [to] the mental status of patients in early adolescence and adulthood" (Kita \& Hosokawa, 2011, p. 148). It was additionally observed from Paolo Fusar-Poli, M.D. and Pierluigi Politi, M.D., Ph.D. that autism did not "always and only occur in young people" (Fusar-Poli \& Politi, 2008).

Perception explains the way autism is diagnosed today. Currently, behavior remains the gold standard of diagnosis of autism (Chen, Penagarikano, Belgard, Swarup, \& Geschwind, 2015) (Murray, Autism, 2011). Others cannot conclude that another is autistic without a perception of that behavior. This is problematic for several reasons. To begin with, social impairment isn't an entity that can be quantified (Evans, 2017). Additionally, an individual can change their behaviors through their choices thus not exhibiting the very characteristics that would bring an individual to conclude that they are autistic to begin with. Besides, patterns of behavior do not always denote pathology, a notion verified by Fred Volkmar who said that "odd and unusual behaviors do not, in and of themselves, constitute a 'disorder' unless they are related to a manifestation of serious dysfunction within the individual" (Silberman, 2015, p. 397). 
Regardless of these issues, perception helps to play a role in the creation of the Autism Spectrum Disorder because without a mechanism of pathology, any behavior or description can be utilized to describe varying degrees of autism. In fact, it has been said that "anything and everything can, it seems, be seen to be autistic" (Murray, Autism, 2011, p. 43). In fact, in the past "some of the very high functioning kids now called autistic would have been called weird or unusual" (Grinker, 2007, pp. 167-168). Even typos in the DSM-IV influenced the perception of diagnosticians to increase the number of those diagnosed with autism according to the mistyped criteria (Grinker, 2007) (Silberman, 2015). Perception explains why some societies "do not even have a word for autism" (Grinker, 2007, p. 3) which then lead some epidemiologists in the 1970s and 1980s to suggest "autism was not a universal phenomenon but 'an illness of Western civilization"' (Grinker, 2007, p. 154). Thus, it is perception which drives the psychology of the masses.

The role of perception in autism is powerful. It helps to explain where autism is found as the incidence of autism is highest amongst those that aware of it and suspect it in others. Consequently, this unfortunately means that autism is therefore transmitted $100 \%$ through suspicion. It is even entirely possible that perception in and of itself is what drove the evolution of autism into what it is today. However, this analysis is beyond the scope of this text.

\section{Perception as a Cure for Autism}

A particularly important observation of autism is that there isn't any mechanism of pathology through physiology known at this time. In fact, a contemporary of Eugen Bleuler by the name of Dr. August Hoch, a "professor of Psychiatry [at] Cornell University Medical College, and Director of the Psychiatric Institute, Ward's Island, New York" (Dr. Hoch, 1912, p. 238) mentioned that Bleuler "has very little to offer in the way of etiology" (Dr. Hoch, 1912, p. 
242). Since no mechanism of pathology for autism has existed since Bleuler's time, it can safely be argued that perception plays a major role in its epidemiology. This should be considered in addition to the several to many reasons suggested for this epidemic in the book Unstrange Minds by Roy Grinker. The lack of a mechanism of pathology successfully explains why the symptoms of autism "vary widely from person to person" (Centers for Disease Control and Prevention, 2017). Perception also helps to explain why autism has evolved through time. In contrast, diseases of true pathological origin with a mechanism of pathology do not undergo several modifications of the definition of itself, or evolve, through the course of time.

Perception explains the observation from some that children can seem to grow out of the symptoms of autism (Bates, 2013) (Carpenter, 2015). Thus, with rigorous therapy a child can learn to associate with others in meaningful social ways. This therapy can even be induced by the child themselves by being proactive in learning how to socialize with others. Therefore, a child or an individual can change the self-concept they have of themselves from one of being autistic towards one of being normal. In fact, some have even claimed that a diet containing no yeast helped to remove the symptoms of autism (Dawson, 2015). Though the author does not agree that yeast influences the symptoms of autism, these changes can be accounted for by the fact that this self-induced self-cognitive therapy had a dramatic effect on the social outcome of these individuals. In short, the cure for autism is for individuals to simply change their selfconcept of themselves. These actions, that individuals can change their self-concept of themselves, do not violate any scientific principle, concept, fact, or idea, especially since there is not any mechanism of pathology associated with autism. After all, without a mechanism of pathology, there is not anything physiologically binding an individual to that concept thus 
freeing an individual with the ability to change the perception of themselves to that of a normal individual. Therefore, a previous diagnosis of autism can be completely reversed.

\section{Conclusion}

In conclusion, the notion that autism is caused through literary creativity provides a strong explanation for many of the observations surrounding autism. This notion is strengthened by the fact that no mechanism of pathology has been found including the absence of genetic etiology. Pathology is more than certain not to be found since the very earliest precursor of autism was egocentricity, a non-pathological state. The evolution of autism provides evidence that a mechanism of autism will never be found. The concepts of observer bias and autistic thinking provide evidence that autism came into being through literary creativity.

Additionally, society and the scientific community should strongly consider the positive benefits of autistic thinking spoken of by Eugen Bleuler in his John Hopkins address. These benefits include helping those diagnosed with our modern-day interpretation of autism to feel normal. It also includes creating a fertile environment inside a persons' mind for the generation of new ideas. It can also be a time for a person to unwind after a hard day at work or from a trauma of some sort.

Autism is not the only terms created through the minds of men through literary creativity. Opposition Defiant Disorder (Gotter, 2017) is a condition created to identify individuals who do not do what they are told. Just like autism, this condition is diagnosed based upon the behavior of an individual and does not have a mechanism of pathology. Additionally, Ian Hacking validates this concept of creating conditions through literary creativity when at his lecture given at The British Academy with the title of "Kinds of People; Moving Target" he elaborates that there are engines of discovery for making up of people (Hacking, 2006) thus classifying 
individuals into categories and labels. Therefore, when an individual is diagnosed with autism, they are classified into categories of people that some have even referred to as being alien (Murray, Autism and the posthuman). This has the unintended consequence of inhibiting those individuals to connect with other individuals.

Some individuals may object to the idea that autism came about due to literary creativity and still believe that it is due to a biological cause. They believe this even though for nearly 110 years, from its inception to now, no biological cause has manifested itself on its own. This is a valid scientific data point. Those individuals should consider the words of Claude Bernard when it was mentioned that "when we meet a fact which contradicts a prevailing theory, we must accept the fact and abandon the theory, even when the theory is supported by great names and generally accepted" (Bernard, 1927, 1865). Applying this quote from Claude Bernard towards autism should be considered, especially to the idea that it is due to a biological cause. Additionally, the history of phlogiston (Labinger \& Weininger, 2005) in the early days of chemistry discovery is somewhat applicable to autism. Phlogiston was the answer to everything chemically, except that it did not exist.

In the course of human history, needless and unnecessary human suffering has come about due to individuals applying labels to other individuals. Therefore, to minimize this type of human suffering, it is best that labeling is kept to a minimum, or even better, not done at all. A great example where labels eventually led to suffering occurred when Hans Asperger utilized autism as an excuse to euthanize children (Sheffer, 2018) (Czech, 2018). These actions were celebrated by the Gestapo during World War II (Sheffer, 2018) (Czech, 2018). Autism was also described as a label by Uta Frith when she said that "Kanner introduced the label early infantile autism" (Frith, 1991, p. 5). When autism as a label is applied to an individual, it is generally 
perceived as being negative and is hardly ever perceived as being positive or equal to that of a normal individual. This notion is verified by the fact that it has a tragic impact on families with individuals who are diagnosed with autism (Murray, Representing autism, 2008). In fact, it has been mentioned that "autistic cyberspace is full of personal accounts pointing to how hospitals or schools have inflicted great damage on individuals and their sense of self" (Murray, Representing autism, 2008, p. 17). A great example of this is provided through the experiences of Ari Ne'eman:

"After his Asperger's diagnosis at age twelve, he had to leave that school, which he loved. He hadn't changed, but the attitudes of everyone around him seemed to be transformed overnight. 'Suddenly I went from being someone that people believed had a lot of potential,' Ne'eman recalls, 'to someone who surprised people by any positive attribute that I might display. Before, everyone focused on the things that I was good at, the things that I wanted out of life, and the subjects I was interested in. After I was diagnosed, everybody focused on the things I struggled with, and the things that made me different, which were often the same things that people had framed as positive before. All of a sudden, the kinds of opportunities that I was offered changed tremendously."' (Silberman, 2015, p. 458)

Additionally, it has been said that the diagnosis of autism does not enhance the lives of those diagnosed with autism but instead makes "their lives worse" (Grinker, 2007, p. 66). This label is even perceived as being a disability as is evidenced by the fact that autism is listed as a disability on job application forms. This labeling is unfortunately even done to young children before they have had time to establish their identity, their intelligence, and their personality.

Therefore, the best and most logical action to take to minimize this negativity is to completely cease the diagnosis of autism altogether to prevent unnecessary tragedy in the lives of others. This is most consistent with following the Hippocratic Oath which dictates to do no harm (Tyson, 2001). This will give individuals the benefit of not living with the negative stigma, and all that comes with that negative stigma, which is associated with the diagnosis of autism. It is 
also recommended that diagnostic criteria be removed from all diagnostic manuals. If there is no question that secular changes "wrought to the DSM criteria were the primary factor responsible for rising numbers" (Silberman, 2015, p. 421), then the opposite is true that there should be no question that removing or restricting the diagnostic criteria will drop the numbers of those diagnosed with autism. Doing this will also help to give less credibility to the false notion that autism is caused by vaccines (see Appendix E) even though this notion did not originate through the diagnostic criteria. It is recognized there are those that get specialized benefits once they are diagnosed with autism (Grinker, 2007). It is strongly recommended that these services and benefits be available to all who desire to receive them regardless of, and even in the absence of, a diagnosis. This should be the case if in the future the diagnosis of autism goes away. This way individuals can live both without the diagnosis of autism and receive all the benefits and services that they need. Other vehicles by which individuals can receive these services can include beneficial legislation, service performed by companies, and volunteer groups to aid children. Additionally, it is recommended that aberrant or abnormal behaviors are addressed individually to create an environment where an individual can improve over time.

Virtually anyone can describe a set of aberrant or abnormal behavior and put a name to it. However, this description of abnormal behavior, without a description or explanation of a mechanism of pathology, does not serve to help the well-being of individuals. Future descriptions of abnormal behavior should include mechanisms of pathology backed up with scientific data to prevent individuals from living with any unnecessary discomfort and it is recommended that diagnosing of autism should only occur if there is a known mechanism of pathology. Karl Bonhoeffer discussed that there is a "deceptively seductive power of naming a condition" (Silberman, 2015, p. 145). He said: 
The problem with labels...is that they seem to correspond to disease entities that live independently of the patient, like types of viruses or bacteria. But in psychiatry, labels describe constellations of behavior that can be related to any number of underlying conditions.

(Silberman, 2015, p. 145)

Additionally, in the future, it is best to let pathology present itself on its own thus preventing a mistake or an error like autism from occurring again. Doing this could have prevented the confusion over the years between childhood schizophrenia and autism (Feinstein, 2010). Likewise, it could have prevented the confusion between autism as a condition and autism as a way of thinking. It could have also prevented the "welter of competing labels in use by various clinicians" (Silberman, 2015, p. 340).

Autism should not exist to advance individuals' careers (Evans, 2017). After all, the selfconcept that people have of themselves is on the line and all individuals should see fit to choose for themselves how they wish to perceive themselves. Though it is true that the idea of autism exists in our historical documents, it should not be utilized to dictate the psychology of the masses, especially since it can bring the sense of tragedy to those affected by it. It especially should not be used as an excuse to conduct eugenics or terminate pregnancies, especially given the fact that it originates from egocentricity, a condition that all individuals experience (Murray, Autism, 2011).

If humanity is ever to rid itself of the modern day understanding of autism then humanity as a whole needs to treat autism the way psychologists do with "the white bear problem" (Vilhauer Ph.D., 2015). Implications from this "white bear problem" suggest that it would be wise to not pay attention to autism simply by focusing on other things. Those currently diagnosed with autism will have to perform their own self cognitive therapy to transform the way 
that they perceive themselves from that of being autistic to that of a normal individual. In short, our modern-day society should not take autism so seriously. 


\section{Acknowledgments}

The author sincerely thanks Loic Anthian and Holly Dixon Martinez for their assistance, support, and input. The author especially thanks Bonnie Evans, a respected author of a book and several articles on autism, for her feedback, support, and suggestions on how to improve this manuscript.

\section{Funding}

This research received no specific grant from any funding agency in the public, commercial, or not-for-profit sectors.

\section{Conflict of Interest}

The author declares that the research was conducted in the absence of any commercial or financial relationships that could be construed as a potential conflict of interest. 


\section{References}

Anthian, L. (2017, 06 28). French language interpretation assistance. (B. Beames, Interviewer)

Asperger, H. (1991). 'Autistic psychopathy' in childhood. In U. Frith, Autism and asperger syndrome (pp. 37-92). Cambridge University Press. Retrieved 12 04, 2019, from https://web.archive.org/web/20181027085903/http://4gp.me/bbtc/1540630579666.pdf

Autism Independent UK. (2017, 10 09). Hans asperger - definition. Retrieved from https://www.autismuk.com/home-page/history-of-autism/hans-asperger-definition/

Barahona-Correa, J. B., \& Filipe, C. N. (2016, 01 25). A Concise History of Asperger Syndrome: The Short Reign of a Troublesome Diagnosis. Frontiers In Psychology, 1-7. doi:10.3389/fpsyg.2015.02024

Bates, C. (2013, 01 15). Children can grow out of autism: Controversial research suggests not all youngsters have the same fate. (Associated Newspapers Ltd) Retrieved from DailyMail.com: http://www.dailymail.co.uk/health/article-2262822/Children-GROWOUT-autism-claim-scientists.html

Bernard, C. $(1927,1865)$. An introduction to the study of experimental medicine (1957 Dover ed.). (H. C. Greene, Trans.) Macmillan \& Co., Ltd.

Bleuler, E. (1911, 1950). Dementia praecox or the group of schizophrenias. (M. J. Zinkin, Trans.) New York, New York: International Universities Press, Inc.

Bleuler, E. (1912, 07). Autistic Thinking. The American Journal of Insanity, 69, 873-886. Retrieved from 
https://play.google.com/books/reader?id=d9o1AQAAMAAJ\&printsec=frontcover\&outp $\mathrm{ut}=$ reader $\& \mathrm{hl}=\mathrm{en} \& \mathrm{pg}=\mathrm{GBS} . \mathrm{PA} 887$

Bleuler, E. (1916). Lehrbuch der psychiatrie. Berlin: Julius Springer. Retrieved 12 07, 2019, from https://archive.org/details/Bleuler_1916_Lehrbuch

Brown, S. (2010, 12). Likert scale examples for surveys. Retrieved 09 06, 2018, from Iowa State University Extension and Outreach: https://www.extension.iastate.edu/Documents/ANR/LikertScaleExamplesforSurveys.pdf

Carpenter, S. (2015, 09 09). Life after autism. Retrieved from Slate: http://www.slate.com/articles/health_and_science/medical_examiner/2015/09/is_autism_ permanent_some_children_diagnosed_with_autism_seem_to_grow_out.html

CBC News. (2012, 07 14). Autistic man survives 3 weeks lost in Utah desert. Retrieved from http://www.cbc.ca/news/world/autistic-man-survives-3-weeks-lost-in-utah-desert-

\subsection{6}

Centers for Disease Control and Prevention. (2017, 03 10). Autism spectrum disorder (ASD). Retrieved from https://www.cdc.gov/ncbddd/autism/signs.html

Centers for Disease Control and Prevention. (2020, 04 08). What is fragile x syndrome. Retrieved 06 10, 2020, from Fragle X Syndrome (FXS): https://www.cdc.gov/ncbddd/fxs/facts.html

Chen, J. A., Penagarikano, O., Belgard, T. G., Swarup, V., \& Geschwind, D. H. (2015). The Emerging Picture of Autism Spectrum Disorder: Genetics and Pathology. Annual Review of Pathology: Mechanism of Disease, 111-144. 
Cox, F. E. (2010, 02 01). History of the Discovery of the Malaria Parasites and Their Vectors. Parasites \& Vectors, 3(5). doi:10.1186/1756-3305-3-5

Czech, H. (2018). Hans Asperger, National Socialism, and "Race Hygiene" in Nazi-Era Vienna. Molecular Autism, 1-43. doi:https://doi.org/10.1186/s13229-018-0208-6

Dawson, M. (2015, 06 17). The miracle that cured my son's autism was in our kitchen. Retrieved from New York Post: https://nypost.com/2015/06/17/is-diet-the-key-to-curing-autism/

Dr. Hoch, A. (1912, 05 15). Review of Bleuler's Schizophrenia. N. Y. State Hospitals Bulletin, 5(1), 238-259. Retrieved 11 17, 2017

Evans, B. (2017). The metamorphosis of autism. Manchester: Manchester University Press.

Feinstein, A. (2010). A history of autism: Conversations with the pioneers. Chichester, West Sussex, United Kingdom: John Wiley \& Sons, Ltd.

Fox News. (2012, 07 13). Autistic man, 28, found alive after being lost for 3 weeks in remote Utah desert. Retrieved from http://www.foxnews.com/us/2012/07/13/autistic-mansurvives-3-week-ordeal-in-utah-desert/

Frith, U. (1991). Asperger and his syndrome. In U. Frith, \& U. Frith (Ed.), Autism and asperger syndrome (pp. 1-36). Cambridge University Press. doi:http://dx.doi.org/10.1017/CBO9780511526770.001

Fronteirs. (2017, 09 25). Newly revealed autism-related genes include genes involved in cancer: Using a computational technique that accounts for how genes interact, scientists revealed genes that may be related to autism spectrum disorder. Retrieved 10 19, 2017, from ScienceDaily: https://www.sciencedaily.com/releases/2017/09/170925095436.htm 
Fusar-Poli, M. P., \& Politi, M. P. (2008, 11). Paul Eugen Bleuler and the Birth of Schizophrenia (1908). American Journal of Psychiatry, 165(11), 1407. Retrieved from http://ajp.psychiatryonline.org/doi/pdf/10.1176/appi.ajp.2008.08050714

GoodTherapy.org. (2017, 09 08). Observer bias. Retrieved from http://www.goodtherapy.org/blog/psychpedia/observer-bias

Google, Inc. (2017, 06 19). Google translate. Retrieved from https://translate.google.com/

Google, Inc. (2020, 01 20). Google translate. Retrieved from https://translate.google.com/

Gotter, A. (2017, 05 01). What is oppositional defiant disorder. Retrieved from Healthline.com: https://www.healthline.com/health/oppositional-defiant-disorder

Grinker, R. R. (2007). Unstrange minds. New York: Basic Books.

Hacking, I. (2006, April 13). Kinds of people: Moving targets. Retrieved from The British Academy: https://www.thebritishacademy.ac.uk/sites/default/files/hacking-draft.pdf

Immunization Action Coalition. (2020, 04 06). Vaccine timeline. Retrieved 06 10, 2020, from https://www.immunize.org/timeline/

Kanner, M. L. (1943). Autistic Disturbances of Affective Contact. Nervous Child, 2, 217-250. Retrieved from http://simonsfoundation.s3.amazonaws.com/share/071207-leo-kannerautistic-affective-contact.pdf

Kanner, M. L. (1949, 07). Problems of Nosology and Psychodynamics of Early Infantile Autism. American Journal of Orthopsychiatry, 416-426. doi:10.1111/j.1939-0025.1949.tb05441.x 
Kanner, M.D., L. (1944). Early Infantile Autism. The Journal of Pediatrics, 25(3), 211-217. doi:https://doi.org/10.1016/S0022-3476(44)80156-1

Kanner, M.D., L. (1965). Infantile Autism and the Schizophrenias. Behavioral Science, 10(4), 412-420. doi:10.1002/bs.3830100404

Kita, Y., \& Hosokawa, T. (2011). History of Autism Spectrum Disorders. 147-166. Retrieved from http://www.sed.tohoku.ac.jp/library/nenpo/contents/59-2/59-2-09.pdf

Labinger, J. A., \& Weininger, S. J. (2005). Controversy in Chemistry: How Do You Prove a Negative? The Cases of Phlogiston and Cold Fusion. Angewandte Chemie International edition in English, 44, 1916-22. Retrieved from http://beckmaninstitute.caltech.edu/labinger/nontechpdfs/14CinC2.pdf

Lefton, L. A. (1994). Psychlology (5th ed.). Needham Heights, MA: Allyn and Bacon.

Maatz, M. M., Hoff, M. P., \& Angst, M. J. (2015). Eugen Bleuler's Schizophrenia—A Modern Perspective. Clinical Research, 43-49. Retrieved from https://www.ncbi.nlm.nih.gov/pmc/articles/PMC4421899/

Marusteri, M., \& Bacarea, V. (2010). Comparing Groups for Statistical Differences: How to Choose the Right Statistical Test? Biochemia Medica, 20(1), 15-32. doi:10.11613/BM.2010.004

Mason, G. W., Griffen, D. T., Merrill, J. J., \& Thorne, J. M. (1997). Physical science concepts (2nd ed.). Provo, Utah, United States of America: Brigham Young University Press.

Matuszek, G., \& Talebizadeh, Z. (2009, 09 24). Autism Genetic Database (AGD): A Comprehensive Database Including Autism Susceptibility Gene-CNVs Integrated With 
Known Noncoding RNAs and Fragile Sites. BMC Medical Genetics, 10(102). doi:10.1186/1471-2350-10-102

McHugh, M. L. (2013). The Chi-Square Test of Independence. Biochemia Medica, 23(2), 143149. Retrieved 09 06, 2018, from http://dx.doi.org/10.11613/BM.2013.018

MedicineNet.com. (2016, 05 13). Medical definition of koch's postulates. Retrieved from http://www.medicinenet.com/script/main/art.asp?articlekey=7105

Moskowitz, A., \& Heim, G. (2011). Eugen Bleuler's Dementia Praecox or the Group of Schizophrenias (1911): A Centenary Appreciation and Reconsideration. Schizophrenia Bulletin, 37(3), 471-479. doi:10.1093/schbul/sbr016

Murray, S. (2008). Representing autism. Liverpool: Liverpool University Press. Retrieved from https://www.academia.edu/1160822/Representing_Autism_Culture_Narrative_Fascinatio n

Murray, S. (2011). Autism. (L. Davis, Ed.) New York: Routledge. Retrieved from https://www.academia.edu/1160813/Autism

Murray, S. (n.d.). Autism and the posthuman. United Kingdom. Retrieved 01 21, 2020, from https://www.academia.edu/5182375/Autism_and_the_Posthuman

National Institute of Health. (2020, 06 09). Fragile x syndrome. Retrieved 06 10, 2020, from U.S. National Library of Medicine: https://ghr.nlm.nih.gov/condition/fragile-x-syndrome

Oxford Dictionaries. (2017, 06 02). Egocentric. Retrieved from https://en.oxforddictionaries.com/definition/egocentric 
Ozdemir, T., \& Eyduran, E. (2005). Comparison of Chi-Square and Likelihood Ratio Chi-Square Tests: Power of Test. Journal of Applied Sciences Research, 1(2), 242-244. Retrieved 09 10, 2018, from http://www.aensiweb.com/old/jasr/jasr/242-244.pdf

Piaget, J. (1959). The language and thought of the child (Third ed.). (M. Gabain, \& R. Gabain, Trans.) New York: Routledge \& Kegan Paul Ltd. Retrieved from http://www.abebe.org.br/wp-content/uploads/Jean-Piaget-Language-and-Thought-of-theChild-1998.pdf

Piattelli-Palmarini, M. (1994). Inevitable illusions: How mistakes of reason rule our minds. (M. Piattelli-Palmarini, \& K. Botsford, Trans.) New York, New York, United States of America: John Wiley \& Sons, Inc.

Plotkin, S. (2014, 08 26). History of Vaccination. Proceedings of the National Academy of Sciences of the United States of America, 111(34), 12283-12287. doi:https://doi.org/10.1073/pnas.1400472111

Productions, I. (Producer). (2005). The search for the northwest passage [Motion Picture]. Retrieved 09 11, 2018, from https://www.youtube.com/watch?v=M1I79u5Y9n4

Reed, G. M., First, M. B., Kogan, C. S., Hyman, S. E., Gureje, O., Gaebel, W., . . Saxena, S. (2019). Innovations and Changes in the ICD-11 Classification of Mental, Behavioural and Neurodevelopmental Disorders. World Psychiatry: Official Journal of the World Psychiatric Association (WPA), 18(1), 3-19. doi:10.1002/wps.20611 
Research Autism. (2018, 06 27). Diagnostic criteria. Retrieved 12 10, 2019, from Research Autism: http://www.researchautism.net/conditions/7/autism-(autism-spectrumdisorder)/Diagnosis

Sheffer, E. (2018). Asperger's children: The origins of autism in nazi vienna (1st ed.). New York, New York, United States of America: W. W. Norton \& Company, Inc.

Silberman, S. (2015). NeuroTribes. New York, New York: Penguin Publishing Group. Retrieved 0201,2020

Slomka, M., \& Doub, J. (2020, 06). A Rare Case of Blastomyces dermatitidis Brain Abscess in an Immunocompetent Host. Medical Mycology Case Reports, 28, 8-11. Retrieved from https://doi.org/10.1016/j.mmcr.2020.03.001

Stat Trek. (2018). Random number generator. Retrieved 09 06, 2018, from https://stattrek.com/statistics/random-number-generator.aspx

The American Psychiatric Association. (2013). The medical/psychiatric diagnosis of autism: The DSM-V criteria. Retrieved 12 04, 2019, from Autism Watch: https://www.autismwatch.org/general/dsm.shtml

Tyson, P. (2001, 03 27). The hippocratic oath today. Retrieved from Kitale Dental Centre: http://kitaledentalcentre.co.ke/wp-content/uploads/2018/05/HIPOCRATES-1.pdf

Vilhauer Ph.D., J. (2015, 12 30). What you can do when you can't stop thinking about something. Retrieved from Psychology Today: https://www.psychologytoday.com/blog/livingforward/201512/what-you-can-do-when-you-cant-stop-thinking-about-something 
Wing, L. (1981). Asperger's Syndrome: A Clinical Account. Psychological Medicine, 11(1), 115-129. doi:10.1017/S0033291700053332

Woodworth, P. R. (1924). Psychology: A study of mental life. New York: Henry Holt and Company. Retrieved from https://books.google.com/books?id=NJopAAAAYAAJ\&dq=inauthor\%3A\%22Robert\%2 0Sessions $\% 20$ Woodworth $\% 22 \& p g=P P 1 \# v=$ onepage $\& \mathrm{q} \& \mathrm{f}=$ false

Worthington Biochemical Corporation. (n.d.). Alcohol dehydrogenase. Retrieved 06 10, 2020, from http://www.worthington-biochem.com/adh/default.html

Zeliadt, N. (2017, 06 30). Is there such a thing as an autism gene? Retrieved from The Washington Post: https://www.washingtonpost.com/national/health-science/is-theresuch-a-thing-as-an-autism-gene/2017/06/30/21f35f00-5ce1-11e7-9fc6c7ef4bc58d13_story.html?utm_term=.b5b8d0f2b57d 


\section{Appendix A}

\section{Some Modern-Day Literary Creativity}

I am now going to elaborate on literary creativity by doing a bit of literary creativity of my own. Before I do that, I wish to discuss what exactly is meant by that. It is simply to use your own imaginative thinking to create words. It should be noted that the words which I personally create will not be found in the dictionary. They are the products of my own mind.

1. The first word I am creating is termed prehistoriclabelia. This word is defined as the practice of applying a label, which is often thought of as a condition or a way of thinking, to those who lived previously before the term was created when those who it was being applied to were completely unaware of this label. This practice is a foolish one to do. Eugen Bleuler did it in his "autistic thinking" speech he gave at John Hopkins when he mentioned that either the Greeks or the Romans did autistic thinking. It has also been done when others have applied the concept of autism to those who lived previously before the term was created. The practice is foolish to do since it invites the question of what label is every single individual in the present suffering from which are labels created in the future by others. Remember, we are not aware of that label because it is created in the future. If the answer is nothing, then the same is true for those who lived previously before the creation of a label thus satisfying the concept of time symmetry spoken of earlier in this manuscript. This means that the person needs to be aware of what they are going through at the time and not retroactively applied to the individual. Please note that I am not referring to sicknesses which have known biological causes and can be observed both physically in our day and in the past. I am, however, referring to those labels such as autism which have no biological etiology. 
2. The second word I am creating is termed the pseudo-symptom. This term is derived from my own experience and observations regarding the reasons why others think others have autism. The pseudo-symptom is simply defined as a set of characteristics or behaviors (symptoms) described to be autistic when it is equally true that these exact same characteristics or behaviors are applicable to that of a normal individual. In other words, this phenomenon, the pseudo-symptom, takes the step of introducing and assuming that there is pathology in processes, or ways of thinking, where originally there was none. The meaning of the prefix pseudo- is "false." The word symptom means "a physical or mental feature which is regarded as indicating a condition of disease." Both this prefix and word were used in conjunction to portray as closely as possible the idea that there are symptoms which are falsely applied to that which is normal.

You can simply identify a pseudo-symptom by looking at the reasons why others think others have autism and to scrutinize those reasons to see if they are equally applicable to those that are normal. To help give an idea of what this is like, I have inserted the following text from a previous version of my manuscript:

The origin of the word "pseudo-symptom" began when questions arose from the author after careful reading of an article produced from both CBC News (CBC News, 2012) and Fox News (Fox News, 2012) with contribution from The Associated Press. In these articles it tells the story of an autistic individual by the name of William Martin LaFever who desired to travel from Boulder, Utah to the small town of Page, AZ (Fox News, 2012). In his quest to get to his destination, he decided that he would travel by hiking along the Escalante River with the end goal in mind of getting a ride by boat the 
rest of the way to Page, AZ. He did this when a much wiser course of action could have included hitchhiking between the two locations (CBC News, 2012). This put him through rough but beautiful country which he was not accustomed to. In addition to this, he was grossly underprepared in terms of the supplies he needed to have. Plenty of commodities such as food and water are necessary if you are to travel by foot for many miles in terrain such as that, especially during the summer months which consists of both hot and dry heat. Additionally, there was a lack of communication between him and his relatives. Therefore, his relatives did not know where he was and how he was attempting to get to his destination. In due time, William became lost, stranded, alone, and desperate. He required help to survive. This help came from Deputy Ray Gardner from the Utah Highway Patrol. He and his helicopter team found him "sitting in the Escalante River about five miles from Lake Powell, barely being able to wave his arms" (Fox News, 2012). According to the article, "Gardner's training in searching for people with autism taught him they are naturally drawn to water, so the helicopter search focused on the Escalante River, the department said" (Fox News, 2012).

It is worth noting that from a wilderness survivalist perspective, hiking along and in the river would have been a much wiser course of action compared to hiking in the middle of the dessert. It at least gave him a sense of direction. It would have also provided a cool respite in protection against heat exhaustion, a real threat found in Southern Utah during the summer months. It also prevented him from hiking unnecessary elevation gain which is something frequently found in the canyon country of Southern Utah. The river would have also provided much needed water which can 
quickly evaporate out of the body in that hot dry heat. All this is written to show that there was at least some good logic to the decision that LaFever made.

It is both interesting and odd that Gardner was trained that people with autism were naturally drawn to water and this brought up a series of questions: Was it true that LaFever just wanted to go that direction regardless of the opportunities that were in front of him, and if so, how is the differentiation between what is autistic and what is normal applied to this question? Could a person not considered autistic make the same decisions no matter how foolish or wise it may have been? Could it have been true that LaFever could have been attracted to the water because he recognized how important it was for his survival? Can it also be true that normal people be drawn to water and not be considered autistic? If autistic people are drawn to water, then wouldn't it be true that all people who are drawn to water are also autistic, including all professional surfers, boaters, fisherman, scuba divers, and even national icons such as Michael Phelps? To conclude that all those individuals in the world are autistic is illogical. Therefore, it was recognized by the author that characteristics ascribed to an autistic person could have just as easily been ascribed to a person considered normal. Thus, the concept of the pseudo-symptom was born.

It is worth noting that this characteristic of autism, to be attracted to water, was not written by either Eugen Bleuler or Leo Kanner. Strangely, it became a characteristic of autism much later. 
3. The third term I am creating is called the Convenient for Yourself Principle. This principle dictates that it is convenient for you when autism is applied to other people, but it suddenly is not when it is applied to you.

4. The fourth term I am creating is adatia (Pronunciation: a - date - ee- uh, the first a is a hard a sound). This term is for those who are currently not married and may or may not be a good thing depending upon where an individual is in their life. This word is simply defined as the state of being without a date.

5. The fifth term I am creating is homeworkprocrastinaria. Do I really need to define that one? It is the state of procrastinating your homework. I have been diagnosed with this from time to time.

6. The sixth term I will create I will use the same sentence structure that Eugen Bleuler did when he created the term autism. The state of not having a computer I term acomputia (Pronunciation: a-compute - ee - uh, the first "a" is a hard "a" sound). I hate having this condition. You cannot live or function in this society when you are diagnosed with this condition.

7. The seventh term I will create is trilobitiasis. The definition of this term is the state of being infected with trilobites. This condition is obviously fictional and is borrowed somewhat from the humor of a brother of mine after I hiked Mount Timpanogos looking for those little critters in the rocks. Although I failed in my attempt to find them up at the 
top of Timp, I was far more successful in finding them in a quarry that a family of a friend of mine owns in Delta, Utah. Some of those specimens found in that quarry are found at the Smithsonian museum of Natural History. I learned a valuable scientific lesson that day as I was digging for them from a guy that worked there by the name of Gene. Gene mentioned to me that to find a big trilobite you need to be willing find the little ones. The same is true for finding major scientific discoveries.

8. Psychologistology is defined as the study of the behavior of psychologists. I consider this to be a rather boring and ridiculous term and I discourage others to use it from both regular and scientific individuals. I do not expect anyone to take this or any other term on this list seriously. However, for the history of autism I do think that studying the behavior of psychologists is important to do as it gives insights into the origins of autism.

9. Vaccine complacency disorder occurs when populations of people become so unacquainted with the horrors of disease that they become complacent with taking vaccines which prevent the disease in the first place.

When it comes to this specific disorder, I am always reminded of Edward Jenner, the individual considered to be the father of immunology. If he were to enter a time machine and transported to our time, I imagine that he would be absolutely stunned and amazed at the technology of vaccines which exists at our time. I also imagine that he would be equally amazed at the fact that there are not more individuals taking advantage of this technology. 
A cure for this disorder in my mind is simply a vigorous educational campaign showing and reminding individuals what these diseases do to individuals. This educational campaign can be done in many of the health classes which exist in the world. This solution has the potential to prevent the syndrome I will describe next.

10. Teenage defiance syndrome is defined as the natural human tendency of all individuals to resist to do something when they are forced to do it even if what they are being forced to do is good for them. If a vaccine is provided I will gladly seek it out to take it to prevent getting the disease but there is a part of me which desires to resist taking it if I am being forced to take it.

Do I really need to create more terms to illustrate my point on what I think what literary creativity is or do you get the idea? If you get the idea and truly know what I am talking about then we need to ask ourselves an honest question which is the following: Is this what Eugen Bleuler did when he created the term autism? Is this what he really did when he introduced the term by saying that "this detachment from reality, together with the relative and absolute predominance of the inner life, we term autism" (Bleuler, Dementia praecox or the group of schizophrenias, 1911, 1950, p. 63)?

If the answer is no, then what evidence do you have to prove that this is not the case? Do you find that Eugen Bleuler made observations of some sort such as the measurement of a temperature or a color change of the patient? Did he write it in a manner which read like modern medical case history reports such as when the fungus specie Blastomyces dermatitidis infected the brain in an immunocompetent host (Slomka \& Doub, 2020). I personally do not think that he 
was doing that because he would have provided these observations and we would have personally seen those observations in individuals in our day. This is the reason why it is my view that biology will never be found. The truth is that biology has not been found for nearly 110 years since its inception and it seems as if no one else has stopped and asked the question as to why or has provided an explanation for this observation. Additionally, diseases tend to manifest themselves on their own. For example, a heart attack, diarrhea, the common cold virus, cancer of all varieties, all tend to manifest themselves on their own. Even PKU (phenylketonuria) manifests itself on its own even though it is hardly in the conscience of most individuals (PKU is tested for on all newborns and has a far lower disease frequency rate than that of autism by the way). You know you have these sicknesses because you feel it or die from them. However, in the history of autism, this has never happened.

Therefore, when it comes to literary creativity, I personally think this is exactly what Eugen Bleuler did. Therefore, when I proposed the idea that autism is caused by literary creativity, I did this based upon the behavior of Eugen Bleuler. It is not a pie in the sky autism comes from alien's idea. It is like saying that the reason why Freud put forth his penis envy theory is because he thought he had an attractive penis. It is like saying the reason Freud came up with the theory that little children enjoy dropping a stool is because he enjoyed dropping his own stool. This is highly likely since, in my view, that which we see in others is subconsciously what we see in ourselves. These ideas cannot be proved scientifically but you cannot rule them out either. The only way which you could prove or disprove these ideas is to talk to Freud directly which is an impossibility at this point due to his death. In my view, looking at the behavior of the individuals who proposed the idea is a very logical thing to do. It recognizes the fact that psychologists have psychology too and that you must figure out their psychology to 
figure out how certain ideologies came to be. In my view, this is something very rarely done, and it is hardly questioned.

By the way, I would have never written a paper indicating that organisms such as Klebsiella pneumoniae, Pseudomonas aeruginosa, Aerobacter aerogenes, Eschericihia coli, or Proteus mirabilis was due to literary creativity. I personally have grown each of those organisms and it would have scientifically been incorrect for me to do so.

This idea, that autism is due to literary creativity, is so simple that it is a fear of mine that others will simply overlook it, not acknowledge it, and discount it. After all, it is a natural human tendency to over-complicate things which is part of the reason why the obvious is so elusive.

It is problematic when everyone treats this literary creativity from Eugen Bleuler as scientific fact when in fact they should not. If individuals are going to treat it as scientific fact, then it needs to be verified from a scientific point of view. The scientific testing which can be done is that which is spoken of in the statistical section of this manuscript. If the scientific testing described earlier in this manuscript dictates it to not cause any pathology, then we should safely relegate autism to that of literary creativity and throw it out as a valid scientific claim. This means that we should not take autism seriously and this includes to stop diagnosing it altogether. The fact that individuals treat this in a scientific manner is evidenced by the fact that it is diagnosed in our day. It is also problematic when individuals do not even recognize that literary creativity is being utilized to create these terms, such as autism.

Some individuals may think it ridiculous that I created those words earlier in this section. However, if these are the actions which Eugen Bleuler did with autism, then those are my thoughts regarding autism exactly. 


\section{Appendix B}

\section{A Discussion on Genetics}

Some have recommended that genetic disorders such as fragile X syndrome, Shank 3, and others must be considered. Remember, we are looking through a window or a lens of about 110 years of human history which Eugen Bleuler simply did not have when he created that term. Therefore, you must keep what he says in context. He coined the term in 1911. It was 1865 when Gregor Mendel introduced the concept of the gene. Later in 1903, the behavior of chromosomes during meiosis was described. It was 1952 that Alfred Hershey and Martha Chase proved that DNA was indeed the genetic material. It was a short time afterwards that Watson and Crick finally elucidated the structure of the DNA molecule. Therefore, when Eugen Bleuler created the term "autism," there was not a lot known about genetics at the time. Additionally, if Eugen Bleuler intended for genetics to be a part of autism, he should have mentioned that. To the author's knowledge, this simply did not happen.

Regarding the genetic diseases spoken of earlier, it is recommended that the scientific community classifies those diseases as separate and distinct from that of autism. This is for a couple of reasons. The first is the numbers. It always seems as if these genetic diseases have a drastically much lower disease frequency compared to the diagnosis rate of autism. This leads to the obvious conclusion that those genetic diseases cannot possibly account for the absolutely huge number of increases in the diagnosis of autism. For example, for fragile $\mathrm{x}$ it mentions that "the exact number of people who have FXS is unknown, but it has been estimated that about 1.4 per 10,000 males and 0.9 per 10,000 females have FXS" (Centers for Disease Control and Prevention, 2020). However, for autism the diagnosis rate is about 1 in 54 according to the CDC as of June 2020. Why the huge discrepancy? Could it be that perception takes a major role to 
account for this huge increase? The second reason why it is recommended that these genetic diseases should be classified separate and distinct from that of autism is due to the differences in the descriptions between these diseases to that of how autism was first conceptualized. For example, the National Institute of Health describes the Fragile X syndrome as the following:

"Most males and about half of females with fragile X syndrome have characteristic physical features that become more apparent with age. These features include a long and narrow face, large ears, a prominent jaw and forehead, unusually flexible fingers, flat feet, and in males, enlarged testicles (macroorchidism) after puberty." (National Institute of Health, 2020)

Do you see any physical observations like this written by Eugen Bleuler describing autism? The answer is obviously, no!

Another little interesting factoid is that Eugen Bleuler considered alcoholism to be a part of the group of schizophrenias. Are people aware of that? Probably more than likely not. Just like the genetic diseases, alcohol dehydrogenase was discovered in 1937 (Worthington Biochemical Corporation, n.d.), much later after Eugen Bleuler wrote about this in his book in about 1911. This means that it would be wise to take most everything what Eugen Bleuler says with a grain of salt as he did not have the technology that we do now. However, if we are going to let that man dictate our psychology to the extent that he already has then it is highly recommended that we label all alcoholics as schizophrenics. This includes all those that are cold-stone sober for 30 years because according to Alcoholics Anonymous, once you are an alcoholic you are always an alcoholic. After all, more labelling is what is needed in this world (this sentence has a high amount of sarcasm and is not intended to be taken seriously).

Here are the exact quotes from Eugen Bleuler regarding alcohol from his book: 
1. "Yet we cannot exclude the possibility that certain mild organic disturbances bring forth symptom complexes which we now designate as dementia praecox. It is possible, furthermore, that some kind of intoxication, for instance, by alcohol, may bring about similar clinical pictures (cf. below). As long as the real disease process is unknown to us, we cannot exclude the possibility that various types of auto-intoxication or infections may lead to the same symptomatic picture."

(Bleuler, Dementia praecox or the group of schizophrenias, 1911, 1950, p. 279)

2. "In certain cases, emotional excitement will serve to activate the disease, in that it may make a latent symptom manifest. There are patients who reveal their pathological chain of ideas, their affective disorder, neologisms and other symptoms only under such conditions. Alcohol may sometimes serve as such an activating factor; it may provoke a typical schizophrenic excitement which, under certain circumstances, may outlast the alcoholic intoxication. However, neither circumstances, may outlast the alcoholic intoxication. However, neither one of these activating factors works in all cases and they cannot be recommended for experimental purposes for various reasons."

(Bleuler, Dementia praecox or the group of schizophrenias, 1911, 1950, p. 297) 


\section{Appendix C}

Diagnostic Criteria for Autism Spectrum Disorder From DSM-V

(As Provided Verbatim Via autism-watch.org From the Following Webpage:

https://www.autism-watch.org/general/dsm.shtml):

1. "Persistent deficits in social communication and social interaction across multiple contexts, as manifested by the following, currently or by history (examples are illustrative, not exhaustive):

a. Deficits in social-emotional reciprocity, ranging, for example, from abnormal social approach and failure of normal back-and-forth conversation; to reduced sharing of interests, emotions, or affect; to failure to initiate or respond to social interactions.

b. Deficits in nonverbal communicative behaviors used for social interaction, ranging, for example, from poorly integrated verbal and nonverbal communication; to abnormalities in eye contact and body language or deficits in understanding and use of gestures; to a total lack of facial expressions and nonverbal communication.

c. Deficits in developing, maintaining, and understanding relationships, ranging, for example, from difficulties adjusting behavior to suit various social contexts; to difficulties in sharing imaginative play or in making friends; to absence of interest in peers.

2. Restricted, repetitive patterns of behavior, interests, or activities as manifested by at least two of the following, currently or by history (examples are illustrative, not exhaustive): 
a. Stereotyped, or repetitive motor movements, use of objects, or speech (e.g. simple motor stereotypes, lining up toys or flipping objects, echolalia, idiosyncratic phrases).

b. Insistence on sameness, inflexible adherence to routines, or ritualized patterns of verbal or nonverbal behavior (e.g. extreme distress at small changes, difficulties with transitions, rigid thinking patterns, greeting rituals, need to take same route or eat same food every day).

c. Highly restricted, fixated interests that are abnormal in intensity or focus (e.g. strong attachment to or preoccupation with unusual objects, excessively circumscribed or perseverative interests).

d. Hyper- or hyporeactivity to sensory input or unusual interest in sensory aspects of the environment (e.g. apparent indifference to pain/temperature, adverse response to specific sounds or textures, excessive smelling or touching of objects, visual fascination with lights or movement).

3. Symptoms must be present in the early developmental period (but may not become fully manifest until social demands exceed limited capabilities, or may be masked by learned strategies in later life).

4. Symptoms cause clinically significant impairment in social, occupational, or other important areas of current functioning.

5. These disturbances are not better explained by intellectual disability (intellectual developmental disorder) or global developmental delay. Intellectual disability and autism spectrum disorder frequently co-occur; to make comorbid diagnoses of autism spectrum 
disorder and intellectual disability, social communication should be below that expected for general developmental level."

(The American Psychiatric Association, 2013) 


\section{Appendix D}

\section{Diagnostic Criteria for Autism Spectrum Disorder From ICD-11}

(As Provided Verbatim Via researchautism.net From the Following Webpage: http://www.researchautism.net/conditions/7/autism-(autism-spectrum-disorder)/Diagnosis):

"Autism spectrum disorder is characterized by persistent deficits in the ability to initiate and to sustain reciprocal social interaction and social communication, and by a range of restricted, repetitive, and inflexible patterns of behavior and interests. The onset of the disorder occurs during the developmental period, typically in early childhood, but symptoms may not become fully manifest until later, when social demands exceed limited capacities. Deficits are sufficiently severe to cause impairment in personal, family, social, educational, occupational or other important areas of functioning and are usually a pervasive feature of the individual's functioning observable in all settings, although they may vary according to social, educational, or other context. Individuals along the spectrum exhibit a full range of intellectual functioning and language abilities.

It also notes that there are several sub-types of autism spectrum disorder:

1) 6A02.0 Autism spectrum disorder without disorder of intellectual development and with mild or no impairment of functional language. All definitional requirements for autism spectrum disorder are met, intellectual functioning and adaptive behaviour are found to be at least within the average range (approximately greater than the 2.3rd percentile), and there is only mild or no impairment in the individual's capacity to use functional language (spoken or signed) for instrumental purposes, such as to express personal needs and desires. 
2) 6A02.1 Autism spectrum disorder with disorder of intellectual development and with mild or no impairment of functional language. All definitional requirements for both autism spectrum disorder and disorder of intellectual development are met and there is only mild or no impairment in the individual's capacity to use functional language (spoken or signed) for instrumental purposes, such as to express personal needs and desires.

3) 6A02.2 Autism spectrum disorder without disorder of intellectual development and with impaired functional language. All definitional requirements for autism spectrum disorder are met, intellectual functioning and adaptive behaviour are found to be at least within the average range (approximately greater than the 2.3 rd percentile), and there is marked impairment in functional language (spoken or signed) relative to the individual's age, with the individual not able to use more than single words or simple phrases for instrumental purposes, such as to express personal needs and desires.

4) 6A02.3 Autism spectrum disorder with disorder of intellectual development and with impaired functional language. All definitional requirements for both autism spectrum disorder and disorder of intellectual development are met and there is marked impairment in functional language (spoken or signed) relative to the individual's age, with the individual not able to use more than single words or simple phrases for instrumental purposes, such as to express personal needs and desires.

5) 6A02.4 Autism spectrum disorder without disorder of intellectual development and with absence of functional language. All definitional requirements for autism spectrum disorder are met, intellectual functioning and adaptive behaviour are found to be at least within the average range (approximately greater than the 2.3 rd percentile), and there is 
complete, or almost complete, absence of ability relative to the individual's age to use functional language (spoken or signed) for instrumental purposes, such as to express personal needs and desires.

6) 6A02.5 Autism spectrum disorder with disorder of intellectual development and with absence of functional language. All definitional requirements for both autism spectrum disorder and disorder of intellectual development are met and there is complete, or almost complete, absence of ability relative to the individual's age to use functional language (spoken or signed) for instrumental purposes, such as to express personal needs and desires."

(Research Autism, 2018) 


\section{Appendix E}

Why the MMR vaccine is not the cause of autism.

It is important to discuss why vaccines are not the cause of autism. It is unfortunate that this ideology came into being to begin with in the first place. It has caused loss of life and unnecessary human suffering. The fact that the cause of autism was pinned onto the MMR vaccine allows us to use some commonsense concepts to eliminate that as the cause. Here are two concepts which are important to know which allow us to eliminate the MMR vaccine as the cause of autism:

1. Everyone understands the concept that the effect of a pill or a drug takes effect after you ingest it or administer it in some way. When it was suggested that the MMR vaccine was the cause of autism, it was suggested the MMR vaccine had a pharmaceutical effect to cause autism. Therefore, if this theory was true, this means that autism should have been discovered after 1971, the year that the MMR vaccine was created. This also means that writings of both Leo Kanner and Eugen Bleuler concerning autism should have never happened because the "true" cause of autism, the MMR vaccine, had not yet been created. However, since the writings of both Leo Kanner and Eugen Bleuler occurred before 1971, we can logically and sensibly eliminate the MMR vaccine as the cause of autism.

(Immunization Action Coalition, 2020) (Plotkin, 2014)

2. The consequence of individuals believing that the MMR vaccine causes autism has caused a net decrease in individuals taking the MMR vaccine. If the MMR vaccine did indeed cause autism and if the rate of individuals taking the MMR vaccine goes down, then it should be logical that the rate of the diagnosis of autism should also go down. However, this is not what happened. The reality is that despite the rates of MMR vaccination going down, the rates of the diagnosis of 
autism has gone up thus demonstrating the MMR vaccine not causing autism. Contrast this with the drug thalidomide. The immediate side effect of taking that drug was birth defects and upon cessation of taking that drug those birth defects went down. 


\section{Appendix F}

Special notes about some of the references

1. The address with the title of "Autistic Thinking" given by Professor Eugen Bleuler at the opening exercises of the Henry Phipps Psychatric Clinic at The Johns Hopkins Hospital in Baltimore, Maryland on April 16-18, 1913 can be found at the following website: https://osf.io/wjure/

A text document at the same website provides instructions on how to get to the speech quickly. This text document, along with the document that contains the address is found in a folder with the name of eugen_bleuler_writings at the above listed website.

What I have find to be amazing about this document is that it seems none of the professional published papers seem to reference this source. This is unfortunate since I find that it gives greater insight into the subject of autism.

2. A version of the textbook that both Hans Asperger and Leo Kanner would have read is provided in the same folder as described in \#1 above in both the English and German languages. It has the name of "The Textbook of Psychiatry."

The English version on page vii mentions the "Autistic Thinking" address spoken of in \#1 above. Beyond that, it does not speak of autism or autistic thinking at all. The German language version does speak of the concept of autistic thinking in the text.

3. The book in the German language called "Dementia Praecox or the Group of Schizophrenias" written by Eugen Bleuler can be found in the same folder described in \#1 above. This document does speak of the concept of autistic thinking. 
The fact that several of the sources above speak of autistic thinking is important. It shows that there are several sources documenting this concept. It is strange to me that individuals in our modern-day seem to not recognize that concept.

4. The book written by Bonnie Evans with the title of "The metamorphosis of autism: A history of child development in Britain (Social Histories of Medicine) 1st Edition” can be found at the following location on Amazon:

https://www.amazon.com/metamorphosis-autism-development-Histories-

Medicine/dp/0719095921/ref=sr_1_1?ie=UTF8\&qid=1513631452\&sr=8-

$1 \&$ keywords=metamorphosis+of+autism+by+bonnie

I found Bonnie Evans' book to be a fabulous resource on the history of Autism and is a must read.

5. A wonderful book on Asperger's Syndrome written by Edith Sheffer called "Asperger's Children" is a must read. After reading this book, I personally came away with thoughts that I wanted nothing to do with Hans Asperger. I felt like what Hans Asperger did was despicable. The book also lays out very clearly that the term Asperger's Syndrome is indeed a label given to people. It can be purchased at the following Amazon website: https://www.amazon.com/gp/product/B076MCVBQH/ref=ppx_yo_dt_b_d_asin_title_o0 $\underline{2 ? \mathrm{ie}=\mathrm{UTF} 8 \& \mathrm{psc}=1}$

6. A Youtube channel called "Defeat Autism For Good" exists which will be updated from time to time. It is found at the following location: 
https://www.youtube.com/channel/UCXhwbunuZLoZw6gDPuiXXww

At the time of this writing, I have a few videos up with a few of them being videos of a few pages of the book "Praecox or the Group of Schizophrenias" written by Eugen Bleuler in the English language. I should have all the quotes from that book quoted in this manuscript in those videos. 


\section{Appendix G}

A Final Notation from the Author and a Charge to the Reader

It is hoped and desired that this paper helps to inform others on the history of autism, to show that autism has evolved through time, and to propose the idea that the cause of autism is due to literary creativity. I hope that the quotes from the past help those diagnosed with autism to feel normal.

I do admit that the primary motivation and reason for me to write this manuscript quite frankly was to help and to serve others, so they do not have to go through the experience of being labeled with autism. This motivation came about after having gone through the experience myself of having the label of Asperger's Syndrome being applied to me back in 2009. The experience was horrible to say the least and was something I do not wish to have others go through. Quite honestly, I wish I had the tools back then so that I could more easily cope with the experience. The tools I speak of are the concepts in this manuscript. After all, I am never going to allow my identity to be dictated by a man who sent children to killing centers in Vienna (Hans Asperger). If I were diagnosed with autism, I would not want my identity to be dictated to me by an individual who in my opinion is confusing to read from (Eugen Bleuler). I would not want my identity to be dictated by a man who contradicts Eugen Bleuler and discouraged the notion that autism is due to degenerative organic causes (Leo Kanner). Yes, I will even boldly say that I do not want my identity to be dictated by another man at all.

It is true that this motivation may bring with it a bias which should be taken into consideration. However, as I indicated in the manuscript, a mechanism of pathology cares not about bias. If you fall off a cliff and break some bones, your bones will break whether you like it 
or not. If you develop leukemia inside your body, it will develop regardless of your political or religious affiliation. Therefore, my own personal bias should matter not.

Despite my biases and inclinations, I also consider myself to be a scientist. Throughout this manuscript, I have called for a more, not a less, scientific approach to autism. It has been my own opinion that a scientific approach towards autism has been severely lacking throughout the history of autism and should have been done as soon as Eugen Bleuler first conceptualized it. If this had been done, it is a personal belief and opinion of mine that the idea of autism would have been thrown out as a true and valid scientific idea.

If in fact, literary creativity is not the cause of autism, and against all odds a biological cause is found, then at the very least human knowledge is advanced and science can move forward to help those involved. Additionally, if a biological cause is found, writing this document still would not have been in vain because it would eliminate the idea that autism is due to literary creativity.

I currently work in the private sector. This means that the writing of this manuscript does not help me at all to get tenure in an academia position which I do not hold.

If there is some editor of a scientific journal who likes this manuscript and would like to publish it in their journal, then I would be happy for them to do so. At this point, I am content with the preprint servers as I am a huge fan of open science. I also like open science because I have a huge passion to bring information and knowledge to those of my readers.

Concerning my reputation, I am not too concerned about it. I figure that if I try to be truthful, honest, transparent, logical, and as scientific as I can be, a good reputation will follow even if it occurs long after I die, which I hope is about another 50 years from now. A good reputation is not $100 \%$ in my control anyway. 
It is a hope of mine that many individuals, even whole and great societies, engages in the societal experiment to not diagnose autism and watch to see if any pathology spontaneously develops. This way, individuals can live comfortably without it and we can experimentally see if biology magically appears which, in my view, is unlikely. I also think it would be great if the knowledge of the original concept of autistic thinking grew to the point where teachers in classrooms would use the phrase "autistic thinking" to encourage their students to pay attention to them more and be more involved or engaged with what the teacher is doing.

Science is a little funny at times because sometimes it takes years for others to acknowledge and see the value of other individuals' work. For example, the work done by Gregor Mendel was ignored for 35 years before the significance of his work was realized and led to what is known today as Mendelian genetics. The same could be true for my work as well.

I have also concluded that there is only so much that one individual can do. However, this is where you, the reader, comes into play. You see, I would like this document to be what I call a self-working document. This means that I would like this document to inspire you to do something as I am minding my own business. I would like this document to inspire you to do something even if it is 100 years from now. I want this document to become your document. These actions I would like you to take can be virtually anything which I hope centers around benefitting both yourself and others. Strangely, these actions do include doing nothing. I like to provide that option of doing nothing to others just to provide a choice as this choice may inspire you to do something. I realize that you may lead a busy life and may not be able to do anything for others. Those diagnosed with autism may choose to have their identity be as "autistic." If so, let them do it. If you are an individual who was diagnosed with autism, I encourage you to begin right away to transition your thinking into that of a normal individual. It will take some 
conscious mental work on your part to do so. I am also a firm believer that individuals can learn to socialize and learn to have meaningful friendships throughout their lives. If you are a relative of an individual who is diagnosed with autism, then I encourage you to not apply that label to them which only serves to put up walls between you and them, resulting in more isolation and less connection. If it so inspires you, download this document, forward it to all your friends and family, and tell them that you support this work. You can also forward it to those professionals who are likely to diagnose autism. Tell them that you support this work and to kindly suggest to them that it is your opinion that it is best to stop diagnosing autism. Be respectful, kind, and polite as you do so. I also encourage you to completely pay for all your bills for services which you have initially requested. Encourage government officials and any other individuals with the resources and power to conduct testing to perform the testing spoken of in the statistical section of this manuscript. This will help to encourage the scientific community to bring a more scientific approach to the concept of autism than what has been done in the past and potentially pave the way to throw out the concept of autism as a valid scientific principle. If you are a professional who supports this work and who has diagnosed autism in the past, maybe it would be a good idea for you to diagnose it a little less, or even better, cease diagnosing it altogether. In other words, I encourage you to do anything which you perceive to have a good effect on others. Good luck to you and everyone else out there. I hope I have done some good, especially for those individuals diagnosed with autism. 